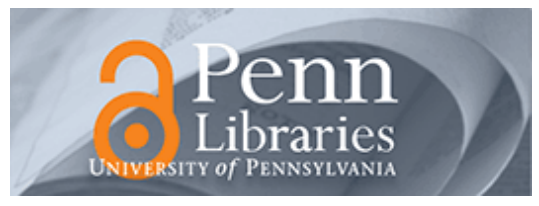

University of Pennsylvania

ScholarlyCommons

Operations, Information and Decisions Papers

Wharton Faculty Research

2-2011

\title{
Is Tiger Woods Loss Averse? Persistent Bias in the Face of Experience, Competition, and High Stakes
}

Devin G. Pope

Maurice E Schweitzer

University of Pennsylvania

Follow this and additional works at: https://repository.upenn.edu/oid_papers

Part of the Other Economics Commons, and the Sports Studies Commons

\section{Recommended Citation}

Pope, D. G., \& Schweitzer, M. (2011). Is Tiger Woods Loss Averse? Persistent Bias in the Face of Experience, Competition, and High Stakes. American Economic Review, 101 (1), 129-157.

http://dx.doi.org/10.1257/aer.101.1.129

This paper is posted at ScholarlyCommons. https://repository.upenn.edu/oid_papers/289

For more information, please contact repository@pobox.upenn.edu. 


\title{
Is Tiger Woods Loss Averse? Persistent Bias in the Face of Experience, Competition, and High Stakes
}

\author{
Abstract \\ Although experimental studies have documented systematic decision errors, many leading scholars \\ believe that experience, competition, and large stakes will reliably extinguish biases. We test for the \\ presence of a fundamental bias, loss aversion, in a high-stakes context: professional golfers' performance \\ on the PGA Tour. Golf provides a natural setting to test for loss aversion because golfers are rewarded for \\ the total number of strokes they take during a tournament, yet each individual hole has a salient reference \\ point, par. We analyze over 2.5 million putts using precise laser measurements and find evidence that \\ even the best golfers-including Tiger Woods-show evidence of loss aversion. \\ Disciplines \\ Other Economics | Sports Studies
}




\title{
Is Tiger Woods Loss Averse? Persistent Bias in the Face of Experience, Competition, and High Stakes
}

\author{
By Devin G. Pope and Maurice E. Schweitzer
}

\begin{abstract}
Although experimental studies have documented systematic decision errors, many leading scholars believe that experience, competition, and large stakes will reliably extinguish biases. We test for the presence of a fundamental bias, loss aversion, in a high-stakes context: professional golfers' performance on the PGA Tour. Golf provides a natural setting to test for loss aversion because golfers are rewarded for the total number of strokes they take during a tournament, yet each individual hole has a salient reference point, par. We analyze over 2.5 million putts using precise laser measurements and find evidence that even the best golfers-including Tiger Woods-show evidence of loss aversion. (JEL D03, D81, L83)
\end{abstract}

A substantial literature has identified systematic ways in which individuals violate standard economic assumptions (see Colin F. Camerer, George Loewenstein, and Matthew Rabin 2004). This literature includes both laboratory and field studies (for reviews, see Camerer 2000; Camerer, Loewenstein, and Rabin 2003; Stefano DellaVigna 2009).

In spite of the extant literature documenting behavioral biases, many scholarsincluding some who have documented behavioral biases-remain skeptical of the claim that biases persist in markets (e.g., John A. List 2003, Steven D. Levitt and List 2008, Sergiu Hart 2005) @ Critics of the decision bias literature believe that biases are likely to be extinguished by competition, large stakes, and experience.

Levitt and List (2008) summarize their concern with the bias literature: "Perhaps the greatest challenge facing behavioral economics is demonstrating its applicability in the real world. In nearly every instance, the strongest empirical evidence in favor of behavioral anomalies emerges from the lab. Yet, there are many reasons to suspect that these laboratory findings might fail to generalize to real markets."

\footnotetext{
* Pope: University of Chicago, 5807 Woodlawn Ave., Chicago, IL 60637 (e-mail: devin.pope@ chicagobooth. edu); Schweitzer: The Wharton School, University of Pennsylvania, 3730 Walnut Street \#566, Philadelphia, PA 19104 (e-mail: Schweitzer@wharton.upenn.edu). We thank Bob Batt for excellent research support and Ken Lovell and Mike Vitti at the PGA TOUR for help with ShotLink data access. We also thank David Abrams, Nick Barberis, Gerard Cachon, Colin Camerer, Stefano DellaVigna, Kirk Doran, Peter Fishman, Adam Galinsky, John Hershey, Daniel Kahneman, Bruce Kothmann, Kory Kroft, Howard Kunreuther, Rob Letzler, Steve Levitt, Cade Massey, Arden Pope, Jaren Pope, Uri Simonsohn, Justin Sydnor, Richard Thaler, Jeremy Tobacman, Maisy Wong, Justin Wolfers, and seminar participants at Carnegie Mellon, the Federal Trade Commission, and The Wharton School for helpful comments and suggestions. We are also grateful to the Wharton Sports Business Initiative for generous funding. All errors are our own.

${ }^{1}$ Despite the fact that List has argued that behavioral biases can be mitigated by economic markets, he has been very open to behavioral work in general (e.g., List 2002; Michael Haigh and List 2005).
} 
In this paper, we examine field evidence of loss aversion, a fundamental bias and a key component of Prospect Theory (Daniel Kahneman and Amos Tversky 1979). We consider a market with high stakes and experienced agents: The PGA Tour. The PGA Tour brings professional golfers together to play in a series of Tournaments each year. In each Tournament, golfers attempt to minimize the total number of shots they take across 72 holes. We focus our attention on putts, the final shots players take to complete a hole. We compare putts golfers attempted for par (the typical number of shots professional golfers take to complete a hole) to putts golfers attempted for scores different from par, such as birdie (one shot less than par). Our sample includes more than 2.5 million putts with laser measurements of initial and final ball placement ( $\mathrm{x}, \mathrm{y}, \mathrm{z}$ coordinates). This is an ideal setting to test for loss aversion. Though golfers should care only about their overall Tournament score, golfers may be influenced by the salient, but normatively irrelevant, reference point of par when they attempt putts.

In contrast to the normative account, we find that golfers are significantly influenced by the reference point of par. When golfers are "under par" (e.g., shoot a "birdie" putt that would earn them a score one stroke under par or shoot an "eagle" putt that would earn them a score two strokes under par) they are significantly less accurate than when they attempt otherwise similar putts for par or are "over par" (e.g., shoot a "bogey" putt that would earn them a score one stroke over par or shoot a "double bogey" putt that would earn them a score two strokes over par). Though we analyze each of these types of putts, most of the putts in our data involve birdie and par putts, and we summarize our results with respect to these putts. For example, on average, golfers make their birdie putts approximately 2 percentage points less often than they make comparable par putts. This finding is consistent with loss aversion; players invest more focus when putting for par to avoid encoding a loss.

Beyond controlling for distance, consider and rule out several competing explanations for this finding. First, prior to hitting a par putt, players may have learned something about the green (by having already attempted a birdie putt). Second, birdie putts may start from a more precarious position on the green than par putts due to a longer approach shot. Third, player or Tournament-specific differences may bias our results. Using detailed data, we are able to rule out competing explanations with control methods and matching estimators. For example, we can match par and birdie putts attempted within one inch of each other on the exact same hole in the same Tournament. We are also able to rule out other psychological explanations. For example, we consider whether or not players become more nervous or overconfident when they shoot birdie putts relative to par putts.

Our finding, that golfers are less accurate when attempting birdie putts than par putts, is moderated by Tournament round. The accuracy gap between par and birdie putts is largest in the first round of the Tournament (first 18 holes) and is less than half as large in the fourth round of the Tournament (last 18 holes). This finding demonstrates that the accuracy gap between par and birdie putts is neither automatic nor immutable. Consistent with our loss aversion account, early in the Tournament, the reference point of par is likely to be very salient; later in the Tournament, alternative reference points, such as the scores of competitors, are likely to become salient.

We also find evidence to support an additional prediction of Prospect Theory: a risk shift. Prospect Theory predicts that economic agents will be more risk averse in 
the gain domain than they are in the loss domain. If professional golfers use par as a reference point, they should be more cautious when putting for birdie (in the gain domain for a specific hole) than when putting for par. Specifically, conditional on missing a putt, we find that golfers hit birdie putts less hard than they hit par putts and are more likely to leave birdie putts short of the hole than par putts. In graphical analysis, we demonstrate that players sacrifice success when putting for birdie to avoid difficult follow-up putts. This pattern of results is consistent with Prospect Theory and decreases expected profits.

Recent theoretical work has conceptualized expectations as reference points (Botond Köszegi and Rabin 2006). Little prior work, however, has directly tested this theory (see Vincent P. Crawford and Juanjuan Meng 2008 and Kirk Doran 2008 for exceptions). In our data, we test for endogenous reference points by considering performance on holes in which players should expect to score either higher or lower than par. Our findings provide evidence consistent with Köszegi and Rabin's (2006) prediction and suggest that expectations influence reference point adoption.

In short, our findings demonstrate that loss aversion persists in a market setting with intense competition, large stakes, and very experienced agents. Even the best golfers_-including Tiger Woods_-exhibit loss aversion.

We organize the paper in the following way: In Section I, we provide background information about loss aversion and professional golf. In Section II, we develop a conceptual framework to understand how loss aversion influences golf performance. In Section III, we describe the data and present our empirical strategy. We report our results and rule out competing explanations in Section IV, and we conclude with a discussion of our findings and their broader implications in Section V.

\section{Background on Loss Aversion and Golf}

\section{A. Prospect Theory and Loss Aversion}

Rather than make consistent decisions over final wealth states, Kahneman and Tversky (1979) postulate that economic agents evaluate decisions in isolation with respect to a salient reference point. In Prospect Theory, Kahneman and Tversky (1979) propose a reference-dependent theory of choice in which economic agents value gains differently than they value losses in two key ways. First, economic agents value losses more than they value commensurate gains (loss aversion); the "value function" is kinked at the reference point with a steeper gradient for losses than for gains. Second, economic agents are risk seeking in losses and risk averse in gains (risk shift); the utility function is convex in the loss domain and concave in the gain domain.

This model of reference dependent preferences has profound implications. If individuals segregate related decisions, they may choose different outcomes. For example, loss aversion and the risk shift may cause an individual to reject a series of small gambles with positive expected return but accept the aggregated gamble. Shlomo Benartzi and Richard H. Thaler (1995) studied this problem in the domain of retirement saving. Benartzi and Thaler (1995) found that people who evaluated their portfolios frequently (and made a series of related decisions) made different hypothetical choices than did people who evaluated their portfolios infrequently. 
Daniel Read, Loewenstein, and Rabin (1999) studied the issue of segregating decisions explicitly and coined the term "narrow bracketing" to describe how individuals segregate or bracket related decisions.

Loss aversion has been documented in many laboratory settings (e.g., Thaler et al. 1997; Uri Gneezy and Jan Potters 1997) and in several field settings (see David Genesove and Christopher Mayer 2001; Camerer et al. 1997; Ernst Fehr and Lorenz Goette 2007; Terrence Odean 1998, and Alex Mas 2006). Some scholars, however, have found evidence to suggest that experience and large stakes may eliminate decision errors (List 2003, 2004).

Our paper makes an important contribution to the literature by documenting loss aversion in a competitive field setting, with large stakes, and very experienced agents. Our paper is also atypical in that we have an unusually large amount of statistical power and a well-defined reference point. In addition, we are able to directly test for evidence of small-scale risk aversion and whether or not reference points change based upon expectations (Kőszegi and Rabin 2006).

\section{B. Professional Golf}

We analyze decisions made by professional golfers playing in the PGA Tour. ${ }^{\text {T }}$ The PGA Tour is a collection of Tournaments (40-50 each year) in which professional golfers (approximately 150 per Tournament) compete. In each Tournament, golfers play 18 holes of golf on each of four consecutive days (four "rounds"). After the second round, golfers with a score that places them in the bottom third are eliminated from the Tournament. All of the remaining players compete in the final two rounds and share the total purse for the Tournament (in 2008 the average purse for each Tournament was approximately $\$ 5$ million). The distribution of payments is highly convex; for example, the winner typically earns 18 percent of the purse.

In golf, players begin by placing a ball on a wooden tee and hitting (or "driving") the ball towards a hole. The players typically end each hole by putting, attempting a short shot on the well-manicured patch of grass (the "green") near the hole. Each player's score is the sum total of his strokes, or hits, across all 72 holes in the Tournament. ${ }^{\text {业 }}$ The player with the lowest score wins the Tournament.

For historical reasons, each hole is assigned a value or "par." On PGA Tour courses, each hole has a par value equal to 3,4 , or 5 . The par value represents the number of strokes that professional golfers often require to finish a hole, and both common golfer parlance and score cards represent performance on each hole with respect to par. Golfers who complete a hole one or two strokes under par have shot a "birdie" or "eagle," respectively. Golfers who complete a hole equal to par have shot par. Golfers who complete a hole one or two strokes over par have shot a "bogey" or "double bogey," respectively. On scorecards, golfers draw a circle for holes they shot under par and a square for holes they shot over par. Scores relative to par are

\footnotetext{
${ }^{2}$ Golf has been used as the context of several papers in economics including Ronald G. Ehrenberg and Michael L. Bognanno (1990), Christopher Cotton and Joseph Price (2006), Jennifer Brown (2007), and Jonathan Guryan, Kory Kroft, and Matthew J. Notowidigdo (2009).

${ }^{3}$ This scoring method is called "stroke play" or "medal play" which is by far the most popular method of scoring in professional golf. However, other scoring systems such as "match play" do exist. Our data consists only of Tournaments that were scored using stroke play.
} 
also quite salient because broadcasters and reporters will often refer to a golfer's score on different holes relative to par. Although it is only performance across the 72 holes that matters, we postulate that par for individual holes will serve as a salient reference point and influence performance.

\section{Conceptual Framework}

We develop a simple conceptual framework to describe the influence that loss aversion may have on putting. When golfers attempt a putt, they can either make the putt and earn a score of $\Delta x$, or miss the putt. For simplicity, we start by assuming that if a golfer misses his first putt, he makes his following putt and earns a score of $\Delta x-1$. In this framework, $\Delta x$ represents the number of strokes (either positive or negative) from par.

We consider the probability of making a putt to be a function of effort, which is endogenously set by the golfer, and other observable putt characteristics. Specifically,

$$
\operatorname{Pr}(\text { makeputt })=f(\mathbf{e}, \mathbf{z})+\varepsilon
$$

where e represents the amount of effort exerted, $\mathbf{z}$ represents a vector of other putt characteristics (e.g., putt distance), and $\varepsilon$ is random noise. We assume that $f^{\prime}$ w.r.t.e $\geq 0$ and $f^{\prime \prime}$ w.r.t. $e \leq 0$ indicating that additional effort weakly increases the probability of making a putt and that $f(*)$ is weakly concave in effort.

In our formulation, we consider the possibility that golfers do not consistently deliver their maximum effort for each putt. Golfers may devote different amounts of effort to their putts throughout the Tournament. This conceptualization is consistent with previous work, which has found that rather than playing consistently across every hole, golfers' performance varies according to the incentives they face (Brown 2007; Ehrenberg and Bognanno 1990). [1

For each putt, golfers derive the following utility:

$$
U=(f(e, z)+\varepsilon) V(\Delta x)+(1-f(e, z)-\varepsilon) V(\Delta x-1)-\operatorname{cost}(e) .
$$

Each golfer's utility is equal to the values placed on making and missing the putt weighted by their probabilities and subtracting the cost of effort, which we assume to be strictly increasing $\left(\operatorname{cost}^{\prime}(e)>0\right)$ and convex $\left(\operatorname{cost}^{\prime \prime}(e)<0\right)$.

Incorporating loss aversion (Kahneman and Tversky 1979), we represent the value function $V(\cdot)$ as

$$
V(\Delta x)= \begin{cases}\Delta x & \text { if } \Delta x \geq 0 \\ \lambda \Delta x & \text { if } \Delta x<0\end{cases}
$$

where $\lambda \geq 1$ is the degree of loss aversion. This value function is a simple version (without diminishing sensitivity in gains or losses) of the value function described

\footnotetext{
${ }^{4}$ This is also consistent with evidence from other sports that suggests that players/teams adjust their effort levels when psychologically discouraged (e.g., Chaim Fershtman and Gneezy 2007) or psychologically motivated (e.g., Jonah Berger and Pope 2009).
} 


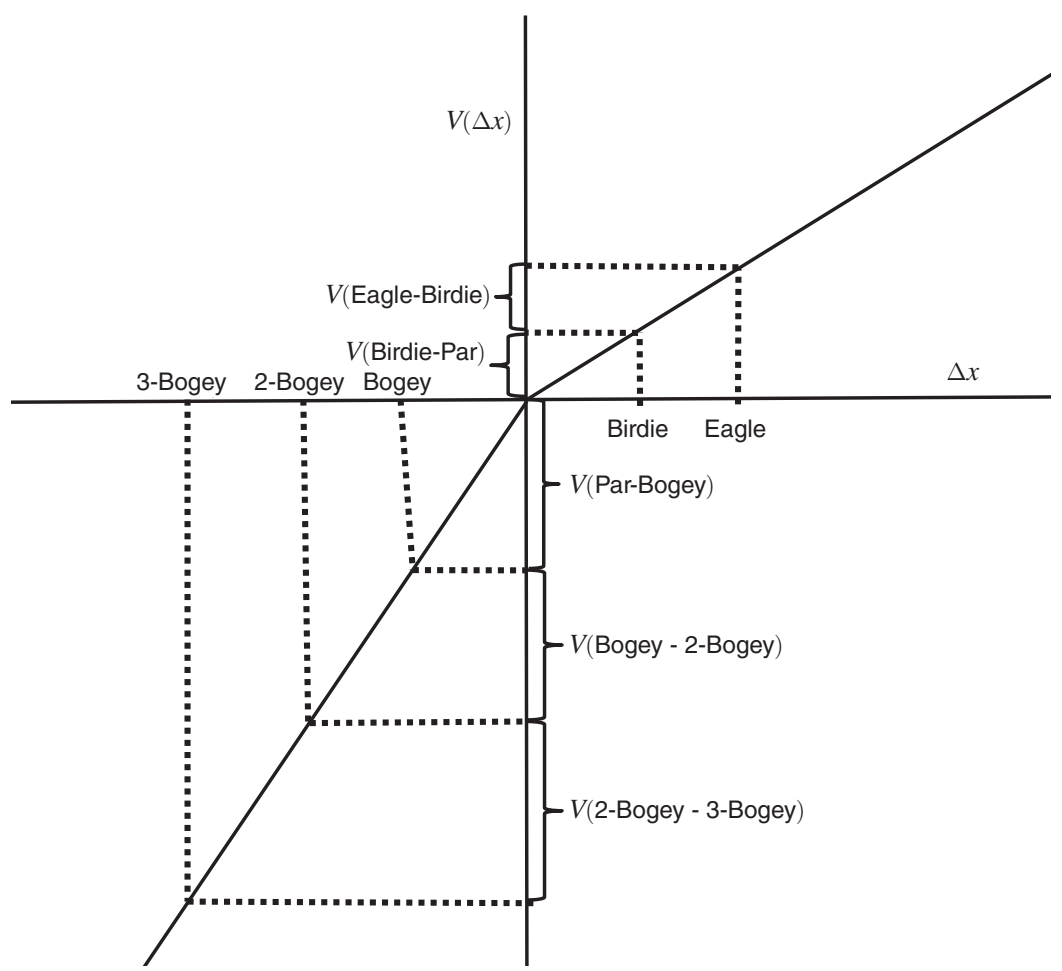

Figure 1. Prospect Theory in the Domain of Golf with Par as the Reference Point

in Prospect Theory and embeds the standard model $(\lambda=1)$. Figure 1 illustrates this value function within the domain of golf. As depicted in the figure, the difference in value between scoring a birdie and a par on a hole is smaller than the difference in value between scoring a par and a bogey. It is also worth noting that we define this value function with respect to each single hole. With this formulation, we implicitly assume that players are narrow bracketing within each hole.

Maximizing the utility function in equation (2) yields the following first-order condition:

$$
\operatorname{cost}^{\prime}(e)=\frac{\partial f(e, z)}{\partial e}[V(\Delta x)-V(\Delta x-1)]
$$

Combining equations (3) and (4) results in the following:

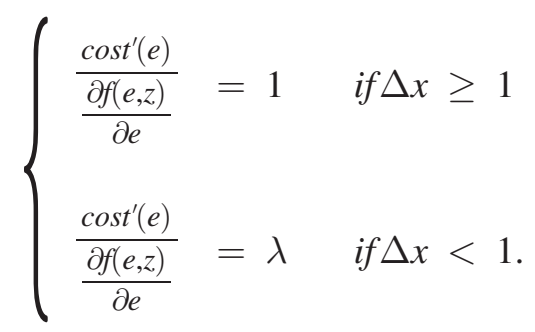


These first-order conditions indicate that a golfer chooses an optimal level of effort, $e^{*}$, by setting the marginal cost of effort equal to the marginal benefit of effort when putting for birdie or eagle $(\Delta x \geq 1)$. However, when putting for par, bogey, or double bogey, the golfer chooses a higher optimal effort level, which equates the ratio of the marginal cost and benefit of effort to $\lambda$.

The first-order conditions imply that players choose higher effort levels in the loss domain (e.g., putting for par, bogey, or double bogey) than they do in the gain domain (e.g., putting for birdie or eagle), and we combine this implication with equation (1) to develop the following testable prediction.

PREDICTION 1: Controlling for putt characteristics, $\mathbf{z}$, putts attempted for par, bogey, and double bogey will be more accurate than putts attempted for birdie and eagle.

In equation (3), we represent a simple, linear value function (Kahneman and Tversky 1979) that contains a loss aversion parameter. Equation (6) extends equation (3) to represent a value function with both a loss aversion parameter and separate risk preference parameters for the gain and loss domains:

$$
V(\Delta x)= \begin{cases}\Delta x^{\alpha} & \text { if } \Delta x \geq 0 \\ -\lambda(-\Delta x)^{\beta} & \text { if } \Delta x<0\end{cases}
$$

In this value function, $\alpha$ and $\beta<1$ are parameters that allow for "diminishing sensitivity." Incremental gains in $\Delta x$ above the reference point result in progressively smaller utility improvements. Conversely, incremental reductions in $\Delta x$ below the reference point result in progressively smaller declines in utility. The curvature of these lines induces players to exert less effort for a putt that is much below or much above par. With diminishing sensitivity (as represented in equation (6)), new firstorder conditions support the following hypotheses.

PREDICTION 2: Controlling for putt characteristics, $\mathbf{z}$, the probability of making a birdie putt is greater than the probability of making an eagle putt. In addition, controlling for putt characteristics, $\mathbf{z}$, the probability of making a par putt is greater than the probability of making a bogey putt, and the probability of making a bogey putt is greater than the probability of making a double bogey putt.

In our conceptual framework, we assumed that if golfers miss their first putt, they will make their following putt. This is empirically common but certainly not automatic. A golfer may miss both the initial and the second putts. We include this possibility to develop a prediction reflecting risk preferences. Compared to risk-seeking putts, risk-averse putts are less likely to drop in the hole but are more likely to set up easy-to-make follow-on putts.

As a result of both the loss aversion and diminishing sensitivity components of Prospect Theory (Kahneman and Tversky 1979), golfers in the domain of gains (golfers attempting eagle or bogey putts) will be more likely to choose risk averse putts than golfers in the domain of losses (golfers attempting par, bogey, or double bogey putts). This leads to our final prediction: 
PREDICTION 3: Controlling for putt characteristics, $\mathbf{z}$, players will be more risk averse when putting for birdie and eagle than when putting for par, bogey, or double bogey.

In the results section, we discuss how we measure risk aversion in the context of golf in order to test Prediction 3.

\section{Data and Empirical Strategy}

To test our predictions, we need to control for putt characteristics, $\mathbf{z}$. This requires access to a rich dataset, which we obtained from the PGA Tour. Since 2002, the PGA Tour has employed approximately 250 workers to gather information each week. Of particular relevance to our investigation, the PGA Tour mounts lasers around each hole of a course to measure every shot each player attempts. These laser measurements record with great precision (within less than one inch) the $\mathrm{x}, \mathrm{y}$, and $\mathrm{z}$ coordinates of the resting position of each ball after every shot. The PGA Tour collected these data to provide information for print journalism, broadcasting, instant online updates, and basic statistics. These data, however, also enable us to test our predictions.

In our analyses, we include data from 239 Tournaments completed between 2004 and 2009. We focus on putts, and we restrict our dataset to putts attempted for eagle, birdie, par, bogey, or double bogey. ${ }^{\mathbf{5}}$ Due to computational constraints, we restrict the data to players for whom we have at least 1,000 putts, leaving us with 2,525,161 putts attempted by 421 professional golfers. In Table 1, we report summary statistics. Most of the putts in our data were for either par (47.0 percent) or birdie $(39.8$ percent). As a result, a large portion of our identification will contrast par and birdie putts.

To test predictions 1 and 2, we compare the probability of making putts with different values relative to par (e.g., bogey, par, birdie, or eagle) that are otherwise similar. Our main specifications take the following form:

$$
\text { Make Putt }_{i j k}=\alpha_{j}+\delta_{k}+\boldsymbol{\beta}\left(\text { Value Relative to } \operatorname{Par}_{i j k}\right)+\gamma \mathbf{Z}_{i j k}+\varepsilon_{i j k} \text {. }
$$

The indicator Make Putt $t_{i j k}$ for each putt $i$, player $j$, and specific hole (in a given round and Tournament) $k$ is represented as a linear function with player and hole fixed effects, a vector of dummy variables indicating the value relative to par (e.g., birdie), a vector of control variables (e.g., distance to the hole), and a random error term.

Our controls in equation (7) enable us to compare otherwise similar putts. For example, we compare birdie and par putts attempted from the same distance to the hole. It is important, however, to note why variation in shot values exists after controlling for distance and other factors. For example, par and birdie putts may

\footnotetext{
${ }^{5} 2,549$ observations $(<0.01$ percent of data) were deleted due to odd data values (e.g., putts attempted more than 1,000 inches from the hole).

${ }^{6}$ Many players played in only one or two Tournaments during our sample period. Since we are running regressions with player fixed effects (as well as hole fixed effects), each player adds to the computational difficulty. Using the entire sample results in regressions that will not run due to space constraints or take weeks to finish. By eliminating players who have few observations, we dramatically reduce the computational demands while eliminating only a small fraction of the total observations.
} 
TABLE 1 -Summary Statistics

\begin{tabular}{lccc}
\hline \hline & Made putts & Missed putts & Full sample \\
\hline Average distance to the hole (inches) & 50.8 & 269.4 & 136.3 \\
Fraction of putts for par & 63.9 & 20.6 & 47.0 \\
Fraction of putts for birdie & 18.5 & 73.1 & 39.8 \\
Fraction of putts for eagle & 0.3 & 3.0 & 1.3 \\
Fraction of putts for bogey & 15.1 & 2.4 & 10.2 \\
Fraction of putts for double bogey & 2.1 & 1.0 & 1.7 \\
Observations & $1,538,198$ & 986,963 & $2,525,161$ \\
\hline
\end{tabular}

Note: This table provides summary statistics for putts taken in the PGA Tour between 2004 and 2009.

be attempted from the same distance on a particular hole. The differences in shot value reflect the accuracy and distance with which prior shots were hit on that hole (e.g., a well-hit versus a badly hit tee shot). After controlling for player and hole fixed effects, we argue that these prior-to-the-putt differences are based on idiosyncratic factors that are unrelated to the putt itself.

\section{Results}

\section{A. Main Effects}

Predictably, distance is a key determinant of putt success. As we plot in Figure 2, the probability of making par and birdie putts declines with distance to the hole. More interestingly, we document a consistent difference between par and birdie putt success. For a given distance, golfers are approximately 2-4 percentage points more likely to make par putts than they are to make birdie putts.

Consistent with Figure 2 and supporting Prediction 1, we report results from logit regression analyses in Table 2 that demonstrate that birdie and eagle putts are less accurate than par, bogey, and double bogey putts. Controlling for distance (Table 2, column 1), putts attempted for birdie or eagle are 2.0 percentage points less likely to be made than putts attempted for par, bogey, or double bogey. This value is statistically significant and has a high degree of precision $(t=43.2)$.

In this regression and across all of our regressions, we include a seventh-order polynomial for distance to the hole. Goodness-of-fit tests suggest that a seventhorder polynomial is necessary and sufficient to control for this important variable.

In column 2 of Table 2, we report results from a logit regression that includes indicator variables for each putt type (e.g., putt for birdie, eagle, bogey, and double bogey). Par serves as the omitted category. Results from this regression suggest that eagle putts are the least likely to be made, followed by birdie putts. These findings are consistent with our second prediction and suggest diminishing sensitivity.

\footnotetext{
${ }^{7}$ In our analyses, we consider the possibility that the quality of earlier shots may influence putt attempts. For example, a golfer may be "having a good day" and thus a good tee shot may be followed by a good putt. Importantly, it is worth noting that this type of positive autocorrelation between shots runs counter to the predictions we make. We consider this and other alternative accounts later in our analyses.
} 


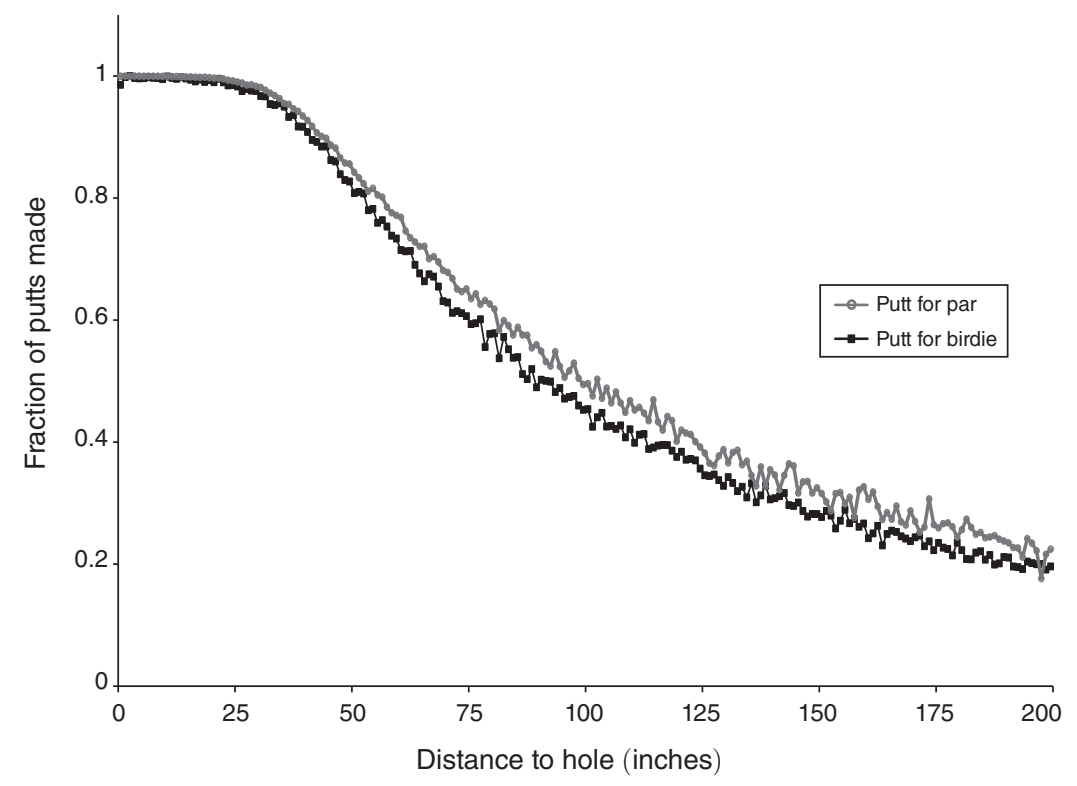

FIGURE 2

Notes: This figure depicts the fraction of successful par and birdie putts by distance to the hole (in inches). The sample includes 2,525,161 putts attempted in the PGA Tour between 2004 and 2008.

Table 2-The Effect of Different Shot Values on Putt Success

\begin{tabular}{lcc}
\hline \hline & $\begin{array}{c}\text { Dependent variable equals 1 if putt was made } \\
\text { Logit estimation }\end{array}$ & $(2)$ \\
\hline Putt for birdie or eagle & $(1)$ & \\
& $-0.020^{* * *}$ & \\
Putt for eagle & $(0.001)$ & $-0.024^{* * *}$ \\
& & $(0.002)$ \\
Putt for birdie & & $-\mathbf{0 . 0 1 9} * * *$ \\
& & $(\mathbf{0 . 0 0 1})$ \\
Putt for bogey & & $0.009 * * *$ \\
& & $(0.001)$ \\
Putt for double bogey & $\mathrm{X}$ & $-0.006 * * *$ \\
& & $(0.002)$ \\
Putt distance: 7 th-order polynomial & $\mathrm{X}$ \\
Pseudo $R^{2}$ & 0.550 & 0.550 \\
Observations & $2,525,161$ & $2,525,161$ \\
\hline
\end{tabular}

Notes: This table reports marginal effects and robust standard errors for the differential success rate of putts of different shot values (par, birdie, etc.) from a logit regression. Column 1 compares putts taken for birdie and eagle relative to the omitted category-putts taken for par, bogey, and double bogey. Column 2 compares each shot value separately relative to the omitted catergory, par.

*** Significant at the 1 percent level.

** Significant at the 5 percent level.

Bogey putts are more likely to be made than par putts, and double bogey putts are slightly less likely to be made than par putts. The coefficient for double bogey putts is consistent with diminishing sensitivity, but the coefficient for bogey putts is not. We revisit this result in the robustness section. 
Table 3-The Effect of Different Shot Values on Putt Success-Robustness Checks

\begin{tabular}{|c|c|c|c|c|c|c|c|c|}
\hline & & & Dependent & $\begin{array}{l}\text { variable equ } \\
\text { (OLS est }\end{array}$ & $\begin{array}{l}\text { uals } 1 \text { if putt } \\
\text { timation) }\end{array}$ & t was made & & \\
\hline & $(1)$ & $(2)$ & (3) & (4) & $(5)$ & (6) & (7) & $(8)$ \\
\hline Putt for eagle & $\begin{array}{l}-0.040 * * * \\
(0.002)\end{array}$ & $\begin{array}{l}-0.039 * * * \\
(0.002)\end{array}$ & $\begin{array}{l}-0.030^{* * * *} \\
(0.002)\end{array}$ & $\begin{array}{l}-0.042 * * * \\
(0.002)\end{array}$ & $\begin{array}{l}-0.039 * * * \\
(0.002)\end{array}$ & $\begin{array}{l}-0.036^{* * * *} \\
(0.002)\end{array}$ & $\begin{array}{l}-0.036^{* * * *} \\
(0.003)\end{array}$ & $\begin{array}{l}-0.064 * * * \\
(0.003)\end{array}$ \\
\hline Putt for birdie & $\begin{array}{l}-0.036 * * * \\
(\mathbf{0 . 0 0 1})\end{array}$ & $\begin{array}{l}-0.036 \text { **** } \\
(\mathbf{0 . 0 0 1 )})\end{array}$ & $\begin{array}{l}-0.026^{* * * *} \\
(\mathbf{0 . 0 0 1})\end{array}$ & $\begin{array}{l}-0.029 * * * \\
(\mathbf{0 . 0 0 1})\end{array}$ & $\begin{array}{l}-\mathbf{0 . 0 2 8} * * * \\
(\mathbf{0 . 0 0 1})\end{array}$ & $\begin{array}{l}-0.028 * * * \\
(0.001)\end{array}$ & $\begin{array}{l}-0.028 * * * \\
(\mathbf{0 . 0 0 1})\end{array}$ & $\begin{array}{l}-0.030 * * * \\
(\mathbf{0 . 0 0 1})\end{array}$ \\
\hline Putt for bogey & $\begin{array}{l}0.004 * * * \\
(0.001)\end{array}$ & $\begin{array}{l}0.005^{* * *} \\
(0.001)\end{array}$ & $\begin{array}{c}0.001 \\
(0.001)\end{array}$ & $\begin{array}{l}0.003^{* * * *} \\
(0.001)\end{array}$ & $\begin{array}{l}0.002 * * * \\
(0.001)\end{array}$ & $\begin{array}{l}0.002 * * * \\
(0.001)\end{array}$ & $\begin{array}{l}0.002 * * * \\
(0.001)\end{array}$ & $\begin{array}{l}0.006^{* * * *} \\
(0.001)\end{array}$ \\
\hline $\begin{array}{l}\text { Putt for double } \\
\text { bogey }\end{array}$ & $\begin{array}{l}-0.007 * * * \\
(0.002)\end{array}$ & $\begin{array}{l}-0.006 * * * \\
(0.001)\end{array}$ & $\begin{array}{c}-0.005^{* *} \\
(0.002)\end{array}$ & $\begin{array}{c}-0.003 \\
(0.002)\end{array}$ & $\begin{array}{c}-0.003 \\
(0.002)\end{array}$ & $\begin{array}{c}-0.003 \\
(0.002)\end{array}$ & $\begin{array}{c}-0.002 \\
(0.002)\end{array}$ & $\begin{array}{c}0.001 \\
(0.002)\end{array}$ \\
\hline $\begin{array}{l}\text { Putt distance: } \\
\text { seventh-order } \\
\text { polynomial }\end{array}$ & $\mathrm{X}$ & $\mathrm{X}$ & $\mathrm{X}$ & $\mathrm{X}$ & $\mathrm{X}$ & $X$ & $\mathrm{X}$ & $\mathrm{X}$ \\
\hline Player fixed effects & & $\mathrm{X}$ & $X$ & $X$ & $\mathrm{X}$ & $X$ & $\mathrm{X}$ & $\mathrm{X}$ \\
\hline $\begin{array}{l}\text { Previous-putts-on- } \\
\text { green effects }\end{array}$ & & & $X$ & $X$ & $\mathrm{X}$ & $X$ & $\mathrm{X}$ & $X$ \\
\hline $\begin{array}{l}\text { Tournament-round- } \\
\text { hole effects }\end{array}$ & & & & $\mathrm{X}$ & & & & \\
\hline $\begin{array}{l}4 \text { hole-location } \\
\text { effects }\end{array}$ & & & & & $\mathrm{X}$ & & & \\
\hline $\begin{array}{l}8 \text { hole-location } \\
\text { effects }\end{array}$ & & & & & & $X$ & & \\
\hline $\begin{array}{l}16 \text { hole-location } \\
\text { effects }\end{array}$ & & & & & & & $\mathrm{X}$ & \\
\hline $\begin{array}{l}\text { Score-on-hole-if- } \\
\text { make-putt effects }\end{array}$ & & & & & & & & $X$ \\
\hline$R^{2}$ & 0.598 & 0.598 & 0.599 & 0.603 & 0.612 & 0.626 & 0.646 & 0.670 \\
\hline Observations & $2,525,161$ & $2,525,161$ & $2,525,161$ & $2,525,161$ & $2,525,161$ & $2,525,161$ & $2,525,161$ & $2,525,161$ \\
\hline
\end{tabular}

Notes: This table reports estimates and robust standard errors for the differential success rate of putts of different shot values (par, birdie, etc.) using OLS. Increasingly precise controls are included in each column including: player fixed effects, dummy variables for the number of putts previously attempted on the green by the golfer and the other golfer in a player's group, fixed effects for each hole in a given round and tournament, fixed effects for 4,8 , and 16 location areas for each hole, and fixed effects for the score if the putt is successful for every hole in a given round and tournament.

*** Significant at the 1 percent level.

** Significant at the 5 percent level.

\section{B. Alternative Classical Explanations}

Though our findings are consistent with loss aversion, we consider a number of alternative explanations. In our next set of analyses, we use a Linear Probability Model rather than the more computational intensive Logit Model, because we include a large number of fixed effects. In our most detailed specification, we include more than 300,000 fixed effects.

To provide a point of comparison, in column 1 in Table 3 we report a simple specification including different putt types and the seventh-order distance polynomial. Reflecting differences between OLS and logit, the estimates in this regression are slightly larger than those in Table 2. Still, the basic findings remain.

Differences in Player Ability.-We first consider player fixed effects. Some players may be good drivers (hitting long shots from the tee to the green) but bad putters, and others may be bad drivers but good putters. If this were true, player differences 
could account for our finding that birdie putts are less accurate than par putts. To address this question, we include player fixed effects, and we report results from this regression in column 2 of Table 3 . We find no significant change in our findings. Still, we include player fixed effects in all future specifications.

Learning.-Alternatively, players may learn about the condition of the green from earlier putts. After putting once, golfers may learn important information about the slope or conditions on the green. Compared to birdie putts, par putts are more likely to be the second putt attempted by a golfer on the green. As a result, par putts may be more accurate than birdie putts, because golfers have learned important information. In fact, it is possible that players may learn important information from watching their partners putt on the green.

To control for learning effects, we include separate dummy variables for the number of putts already attempted on the green by the player and the player's partner ${ }^{\mathbb{8}}$ The results from this specification suggest that learning is important. As we report in column 3 of Table 3, golfers are significantly more likely to make the second and third putts on the green than they are to make otherwise similar first putts on the green. ${ }^{\text {G }}$

By including controls for prior putts on the green, the point estimates for birdie and eagle putts are reduced by 20 to 30 percent. However, the remaining differences attributed to birdie or eagle putts relative to par putts remains highly significant. In all future specifications, we include these controls.

Throughout our analysis, we assume that players do not learn about the green prior to actually putting on the green (at which point we include controls). However, it is possible that players learn by watching their approach shots land and roll on the green. Given that par putts are more likely to have a shorter approach shot than birdie putts, learning from closer approach shots could bias our results. Unfortunately, we are unable to control for the entire dynamic process that leads to a putt because this process itself is what generates our variation. For example, on par 3 holes there is very little variation in par versus birdie putt attempts that had similar approach shots. However, we can observe variation on par 5 holes and some par 4 holes. We restrict our sample to par and birdie putt attempts with very long approach shots (more than 50 or more than 100 yards) where learning about the green is unlikely. In separate regressions, we also include a high-degree polynomial of the distance of the approach shot. Although the point estimates are smaller (0.6-0.8 percent for the birdie coefficient and $0.8-1.0$ percent for the eagle coefficient), we continue to find highly significant differences between par, birdie, and eagle success when we include these controls. 10 These smaller point estimates could reflect learning from approach shots, increased noise due to the lack of variation in the data, or

\footnotetext{
${ }^{8}$ Alternatively, one could restrict the sample of putts to those which are first putts attempted on the green. Performing this analysis yields a coefficient on the birdie dummy nearly identical to the coefficient when simply including dummy variables for the number of own and other shots already taken on the green.

${ }^{9}$ We attribute this effect to learning. However, an alternative psychological phenomenon may be driving this reduction. Golfers may have an aversion to taking three putts to finish a hole. If this were true, golfers may try very hard after missing a putt to avoid a "three putt." Alternatively, golfers may update their reference point once they arrive on the green. This may cause golfers to work harder on a second putt since missing the second putt may be coded as a loss. We are unable to disentangle these accounts from learning about the green.

${ }^{10}$ We also continue to find moderation effects by round and that golfers lay the ball up short on birdie putts.
} 
differences in expectations consistent with Köszegi and Rabin (2006). Kőszegi and Rabin's account suggests that when players expect to perform better, the par-birdie differential should be smaller. In Section IVF, we consider and test this possibility.

As we discuss at the end of the paper, this finding is consistent with the KonszegiRabin prediction that the par-birdie differential should be smaller in situations where players expect to perform better (par 5 holes).

Differences across Holes.-We next consider fixed effects for specific holes. It is possible, for example, that holes with easy fairways have difficult greens and that holes with difficult fairways have easy greens. If this were true, birdie putts may be more common than par putts on holes with difficult greens.

To account for this possibility, we include fixed effects for each of the 17,096 different holes (for a given round and Tournament). 11 We report results from this regression in column 4 of Table 3. By including these fixed effects, our results actually become stronger suggesting that holes with easy fairways may also have easy greens.

Position on the Green.-Although we account for distance, it is possible that birdie putts start from a more precarious position on the green than equally distanced par putts. For example, approach shots to the green may be shorter for par putts than they are for birdie putts, and as a result, players putting for par may be able to avoid difficult spots on the green (e.g., sections of the green with awkward slopes).

The level of detail in our dataset enables us to address this concern. We use the $\mathrm{x}$, $\mathrm{y}, \mathrm{z}$ coordinates to control for putts taken from different positions on the green. To do this, we first divide the area around each hole in each round in each Tournament into four quadrants or "pie pieces." We characterize each putt attempt by quadrant, and we report regression results with dummy variable controls for each quadranthole-round-Tournament in column 5 of Table 3. These fixed effects control for location-specific differences.

We conduct even more precise analyses with finer divisions of the space around the hole. In column 6 of Table 3, we report regression results that include controls for eight "pie pieces" (from dividing the green around each hole into eight sections).

In column 7 of Table 3, we report regression results that include controls for 16 sections that not only cut the green into eight pie pieces but also include a concentric circle of radius 137 inches (the mean putt distance in the data).

From these analyses, we find that certain areas of each green are harder to putt from than other areas. By including location-specific effects, we gain predictive power; the $R^{2}$ in the regressions rises from 0.603 (with no location-specific effects) to 0.646 (16 location-specific effects per hole). 112

More importantly, we find only small declines in point estimates as we control for location-specific effects. Location-specific differences influence overall accuracy, but they cannot account for the differences we observe across putt types.

\footnotetext{
${ }^{11}$ Locations of the hole on each green are typically changed in every round during a Tournament. For this reason, fixed effects for every hole in each round in a Tournament must be included rather than just a fixed effect of each hole in a four-round Tournament.

${ }^{12}$ Adjusted $R^{2}$ values increase by a more modest amount (0.599 to 0.608$)$.
} 
Position in the Tournament.-We next control for each golfer's standing in the Tournament. When golfers attempt birdie or par putts, they may exert different amounts of effort depending upon their standing in the Tournament. For example, it is possible that golfers may be more likely to attempt birdie putts when they are far behind and are exerting less effort.

To account for the possibility that player scores influence our finding, we control for each golfer's score in the Tournament when attempting each putt. We include dummy variables that represent a combination of the hole that a golfer is on and his overall Tournament score if he makes the putt.13 For example, imagine that one golfer attempts a par putt on the second hole of the first round of a Tournament and a second golfer attempts a birdie putt on the same second hole. Imagine further that the first golfer attempting the par putt has a score of -1 from the first hole (indicating that he shot a birdie on the first hole), and the second golfer attempting the birdie putt has a score of 0 going from the first hole (indicating that he shot par on the first hole). These two golfers would both have a fixed effect indicating that if they made their current putts, they would both earn a score of -1 (after two holes). This example illustrates how these fixed effects partition each putt into a bucket of putts that, if made, will place the golfers in the same scoring position in the Tournament.

We report results from this analysis in column 8 in Table 3. We find that our main result is not affected by these additional controls. Even accounting for golfers' score, golfers make birdie putts 3.0 percentage points less often than otherwise similar par putts.

Matching Model.-In addition to conducting parametric analyses with control variables, we conduct nonparametric analyses to test alternative explanations that might account for our findings. Though we lose some statistical power with this approach, we are able to compare par and birdie putts in novel ways.

First, we consider a matching model to compare par and birdie putts taken from the same spot on a particular hole, in a particular round, in a particular Tournament. We begin by creating a list of every par putt in our dataset. We then use a matching algorithm to identify the birdie putt on the same hole-round-Tournament with the shortest linear distance from each par putt. For some holes, there are no birdie putts attempted from a position near a par putt. However, on many holes a birdie and a par putt were attempted from nearly the exact same $\mathrm{x}, \mathrm{y}$, and $\mathrm{z}$ coordinate.

We report results from our matched par-birdie analyses in Table 4. In column 1, we report results from the 2,828 pairs of par and birdie putts that were attempted within one inch of each other. Consistent with our thesis and our parametric results, from the same position on the green golfers made their par putts significantly more often than they made their birdie putts $(88.0$ percent of the time versus 83.5 percent of the time, $\mathrm{p}<0.001)$.

In columns 2-8 we report results from pairs of par and birdie putts that were attempted within two, three, four, five, eight, 12, and 24 inches of each other. With

\footnotetext{
${ }^{13}$ One might imagine other ways to control for a golfer's position in the Tournament (e.g., strokes behind the current leader). The problem, however, with many of these alternatives is that golfers play at different times of the day, and thus a golfer may have the best score at a particular moment in time, but it is simply because other golfers have not yet started the course.
} 
Table 4-Estimates from Matching Par and Birdie Putts

\begin{tabular}{|c|c|c|c|c|c|c|c|c|}
\hline & \multicolumn{8}{|c|}{ Maximum distance between matched par and birdie putts } \\
\hline & $\begin{array}{l}<1 \text { inch } \\
\quad(1)\end{array}$ & $\begin{array}{c}<2 \text { inches } \\
(2)\end{array}$ & $\begin{array}{c}<3 \text { inches } \\
\text { (3) }\end{array}$ & $\begin{array}{c}<4 \text { inches } \\
\text { (4) }\end{array}$ & $\begin{array}{c}<5 \text { inches } \\
(5)\end{array}$ & $\begin{array}{c}<8 \text { inches } \\
(6)\end{array}$ & $\begin{array}{c}<12 \text { inches } \\
(7)\end{array}$ & $\begin{array}{c}<24 \text { inches } \\
(8)\end{array}$ \\
\hline $\begin{array}{l}\text { Fraction of matched } \\
\text { birdie putts made }\end{array}$ & $\begin{array}{c}0.835 \\
(0.010)\end{array}$ & $\begin{array}{c}0.878 \\
(0.005)\end{array}$ & $\begin{array}{c}0.895 \\
(0.003)\end{array}$ & $\begin{array}{c}0.897 \\
(0.002)\end{array}$ & $\begin{array}{c}0.895 \\
(0.002)\end{array}$ & $\begin{array}{c}0.881 \\
(0.001)\end{array}$ & $\begin{array}{c}0.861 \\
(0.001)\end{array}$ & $\begin{array}{c}0.812 \\
(0.001)\end{array}$ \\
\hline $\begin{array}{l}\text { Fraction of matched } \\
\text { par putts made }\end{array}$ & $\begin{array}{c}0.880 \\
(0.009)\end{array}$ & $\begin{array}{c}0.905 \\
(0.004)\end{array}$ & $\begin{array}{c}0.914 \\
(0.003)\end{array}$ & $\begin{array}{c}0.912 \\
(0.002)\end{array}$ & $\begin{array}{c}0.910 \\
(0.002)\end{array}$ & $\begin{array}{c}0.900 \\
(0.001)\end{array}$ & $\begin{array}{c}0.882 \\
(0.001)\end{array}$ & $\begin{array}{c}0.843 \\
(0.001)\end{array}$ \\
\hline $\begin{array}{l}\text { Average distance of } \\
\text { matched birdie putts }\end{array}$ & 49.50 & 39.67 & 36.81 & 36.76 & 36.98 & 39.63 & 43.69 & 53.63 \\
\hline $\begin{array}{l}\text { Average distance of } \\
\text { matched par putts }\end{array}$ & 49.50 & 39.67 & 36.77 & 36.70 & 36.87 & 39.35 & 43.11 & 51.81 \\
\hline Number of pairs & 2,828 & 9,547 & 20,019 & 33,239 & 48,136 & 97,281 & 162,418 & 329,793 \\
\hline
\end{tabular}

Notes: For every par putt in the data, a birdie putt taken on the same hole, in the same round, in the same tournament is matched to the par putt if the distance between the par and birdie putt is less than the indicated amount in the table. We report distances from less than 1 inch to less than 24 inches in columns $1-8$. We report the fractions of matched par and birdie putts that were made along with standard errors. We also report the average distance of the matched par and birdie putts for each distance cutoff.

larger distances, we increase the number of matched pairs, but of course, these matches are less precise. Across these analyses, we find that golfers made their par putts between 1.5 percent and 3.1 percent more often than they made their birdie putts.

The effect sizes of these results are smaller than some of the effect sizes we reported in the parametric analyses (e.g., 3.6 percent in column 1 of Table 3). However, this difference stems from the nature of the putts in our matched sample. Most of the putts in our matched sample are putts very close to the hole (the average putt length for putts in columns 1-8 in Table 4 is only 35-50 inches). Golfers almost always make very short putts, and the difference between the probability of making par and birdie putts for very short putts is small. Thus, while the effect sizes may seem slightly smaller, if we account for the proximity of the putts they actually are not. We illustrate this in the Web Appendix by running analyses similar to Table 3 using the matched data sample. Overall, the results from the matching estimation suggest that our findings are robust to nonparametric controls of distance and green location.

\section{Alternative Psychological Explanations}

Psychological factors can influence putt accuracy (Sian Beilock et al. 2001; Beilock et al. 2004), and in this section we consider two psychological phenomena that might account for our findings: overconfidence and nervousness.

Overconfidence.-Overconfidence can harm performance in a number of domains. For example, overconfidence harms judgment accuracy (Sarah Lichtenstein, Baruch Fischhoff, and Lawrence Phillips 1982; Asher Koriat, Lichtenstein, and Fischhoff 1980), forecast accuracy (Robert Vallone et al. 1990) and investment decisions (Brad M. Barber and Odean 2001). We consider overconfidence as a possible explanation for our findings.

After hitting a well-placed shot, golfers may become overconfident or cocky in a way that harms their performance on their next shot. By construction, birdie putts are more likely to follow well-hit drives than par putts. Therefore, overconfidence 
might account for our finding that golfers exhibit negative autocorrelation (after hitting a good shot, their next shot is likely to be bad).

We test this account by searching for negative autocorrelation in performance. Using methods similar to those used by Cotton and Price (2006), we compare performance across holes. Consistent with Cotton and Price's (2006) results, rather than finding negative autocorrelation, we find positive autocorrelation; when golfers score one stroke less on a hole relative to average performance on a hole, they are likely to score $0.004(\mathrm{p}<0.01)$ fewer strokes than average performance on the next hole. ${ }^{14}$ That is, absent a story of loss aversion, our best evidence suggests positive autocorrelation across shots; overconfidence or cockiness cannot account for our findings.

In addition, overconfidence is inconsistent with the set of ancillary results we report later in the paper. For example, prior research demonstrates that overconfidence promotes aggressive behavior (Camerer and Dan Lovallo 1999). We find that golfers actually hit birdie putts less hard than they hit similar par putts.

Nervousness.-The second psychological account we consider is nervousness. Golfers on the PGA Tour hit putts that have large financial consequences, and prior work has found that people often feel nervous or anxious when they face high stakes (Julie McCarthy and Richard Goffin 2004; Beilock 2008; Dan Ariely et al. 2009). Feelings of nervousness harm performance by disrupting task-focused thinking (Irwin Sarason 1984) and by motivating people to make expedient choices to exit their current situation (Alison Wood and Schweitzer 2010).

If golfers value making a birdie putt more than they value making a par putt, they might get nervous and "choke" when putting for birdie. Similarly, golfers may get nervous when taking a birdie putt because a successful birdie putt may advance a golfer into a better position in the Tournament.

The nervousness account, however, cannot explain our results. First, although amateur golfers may infrequently take birdie putts, professional golfers attempt nearly as many birdie putts as they do par putts. Second, even when successful birdie and par putts both would place golfers in a similar position, golfers are still more likely to make par putts than birdie putts. As we report in column 8 of Table 3, golfers' relative putt accuracy is unaffected by golfers' scores.

The nervousness account is also inconsistent with three aspects of our ancillary results. First, as we demonstrate in the following section, players hit their birdie putts shorter than they hit otherwise similar par putts. Second, we demonstrate that even the best golfers including Tiger Woods exhibit this bias in early rounds of Tournaments. Third, the difference between par and birdie putts diminishes across rounds. Nervousness cannot explain these findings.

Finally, though perhaps least persuasive, we offer anecdotal evidence. Consistent with our thesis, and contradicting the nervousness account, several golfers have stated that they actually value par putts more than they value birdie putts. For example, after playing a round in 2007, Tiger Woods explained, "Any time you

\footnotetext{
${ }^{14}$ We find consistent results using different methods (e.g., with and without player-specific controls and alternative nonparametric methods that correct for problems that arise when using fixed effects and lagged dependent variables).
} 
Table 5-The Effect of Different Shot Values on Putt Success-By Round

\begin{tabular}{|c|c|c|c|c|c|c|c|c|}
\hline & \multicolumn{8}{|c|}{$\begin{array}{c}\text { Dependent variable equals } 1 \text { if putt was made } \\
\text { (OLS estimation) }\end{array}$} \\
\hline & \multicolumn{4}{|c|}{ Full sample } & \multicolumn{4}{|c|}{ 4-round players only } \\
\hline & Round 1 & Round 2 & Round 3 & Round 4 & Round 1 & Round 2 & Round 3 & Round 4 \\
\hline Putt for eagle & $\begin{array}{l}-0.053^{* * *} \\
(0.004)\end{array}$ & $\begin{array}{l}-0.044 * * * \\
(0.004)\end{array}$ & $\begin{array}{l}-0.028 * * * \\
(0.005)\end{array}$ & $\begin{array}{l}-0.031 * * * \\
(0.004)\end{array}$ & $\begin{array}{l}-0.065^{* * *} \\
(0.005)\end{array}$ & $\begin{array}{l}-0.057^{* * *} \\
(0.005)\end{array}$ & $\begin{array}{l}-0.028^{* * *} \\
(0.005)\end{array}$ & $\begin{array}{l}-0.031 * * * \\
(0.004)\end{array}$ \\
\hline Putt for birdie & $\begin{array}{l}-0.038 * * * \\
(0.001)\end{array}$ & $\begin{array}{l}-0.028 * * * \\
(0.001)\end{array}$ & $\begin{array}{l}-0.024 * * * \\
(0.002)\end{array}$ & $\begin{array}{l}-0.021 * * * \\
(0.002)\end{array}$ & $\begin{array}{l}-0.046^{* * *} \\
(0.002)\end{array}$ & $\begin{array}{l}-0.035 * * * \\
(0.002)\end{array}$ & $\begin{array}{l}-0.024 * * * \\
(0.002)\end{array}$ & $\begin{array}{l}-0.021 * * * \\
(0.002)\end{array}$ \\
\hline Putt for bogey & $\begin{array}{l}0.003 * * * \\
(0.001)\end{array}$ & $\begin{array}{l}0.003 * * * \\
(0.001)\end{array}$ & $\begin{array}{l}0.004 * * * \\
(0.002)\end{array}$ & $\begin{array}{l}0.003 * * \\
(0.002)\end{array}$ & $\begin{array}{l}0.003^{* * *} \\
(0.001)\end{array}$ & $\begin{array}{l}0.006^{* * *} \\
(0.001)\end{array}$ & $\begin{array}{l}0.004^{* * *} \\
(0.001)\end{array}$ & $\begin{array}{l}0.003 * * \\
(0.001)\end{array}$ \\
\hline Putt for double bogey & $\begin{array}{c}-0.003 \\
(0.003)\end{array}$ & $\begin{array}{c}-0.004 \\
(0.003)\end{array}$ & $\begin{array}{c}0.001 \\
(0.004)\end{array}$ & $\begin{array}{c}-0.001 \\
(0.004)\end{array}$ & $\begin{array}{c}-0.003 \\
(0.003)\end{array}$ & $\begin{array}{c}0.002 \\
(0.003)\end{array}$ & $\begin{array}{r}-0.004 \\
(0.003)\end{array}$ & $\begin{array}{c}-0.001 \\
(0.003)\end{array}$ \\
\hline $\begin{array}{l}\text { Putt distance: seventh-order } \\
\text { polynomial }\end{array}$ & $\mathrm{X}$ & $\mathrm{X}$ & $\mathrm{X}$ & $\mathrm{X}$ & $\mathrm{X}$ & $\mathrm{X}$ & $\mathrm{X}$ & $\mathrm{X}$ \\
\hline Player fixed effects & $\mathrm{X}$ & $\mathrm{X}$ & $\mathrm{X}$ & $\mathrm{X}$ & $\mathrm{X}$ & $\mathrm{X}$ & $\mathrm{X}$ & $\mathrm{X}$ \\
\hline $\begin{array}{l}\text { Previous-putts-on-green } \\
\text { effects }\end{array}$ & $\mathrm{X}$ & $\mathrm{X}$ & $\mathrm{X}$ & $\mathrm{X}$ & $\mathrm{X}$ & $\mathrm{X}$ & $\mathrm{X}$ & $\mathrm{X}$ \\
\hline Tournament-round-hole effects & $\mathrm{X}$ & $\mathrm{X}$ & $\mathrm{X}$ & $\mathrm{X}$ & $\mathrm{X}$ & $\mathrm{X}$ & $\mathrm{X}$ & $\mathrm{X}$ \\
\hline$R^{2}$ & 0.599 & 0.598 & 0.610 & 0.611 & 0.592 & 0.599 & 0.610 & 0.611 \\
\hline Observations & 791,112 & 773,476 & 477,732 & 469,140 & 440,824 & 440,171 & 477,732 & 469,140 \\
\hline
\end{tabular}

Notes: This table reports estimates and robust standard errors for the differential success rate of putts of different shot values (par, birdie, etc.) using OLS while controlling for several baseline covariates. The coefficients are reported when cutting the data by round. Columns 1-4 indicate coefficients for rounds $1-4$, respectively, when using all putts attempted in all rounds. Columns 5-8 indicate coefficients for rounds $1-4$, respectively, when restricting the sample to putts taken by players that played all four rounds of the tournament. This data restriction adjusts for the sample attrition that takes place in golf tournaments after the second round.

*** Significant at the 1 percent level.

** Significant at the 5 percent level.

make big par putts, I think it's more important to make those than birdie putts. You don't ever want to drop a shot. The psychological difference between dropping a shot and making a birdie, I just think it's bigger to make a par putt."

\section{Differences across Rounds}

The difference in accuracy between par and birdie putts is remarkably robust across a range of parameters including players, position on the green, and players' scores. However, we find that the difference in accuracy between par and birdie putts diminishes considerably, but does not disappear, across rounds.

As we report in Table 5 in columns 1-4, the difference in accuracy between par and birdie putts diminishes monotonically from 3.8 percent in Round 1 to 2.1 percent in Round $4(\mathrm{p}<0.001)$. We find a similar pattern for the discrepancy between the accuracy of par and eagle putts.

Of course, a selection effect could contribute to the round effect that we observe. A third of players do not advance to rounds 3 and 4, and if these players exhibit bias in rounds 1 and 2, the differences we observe in early and later rounds could reflect differences in the population rather than an effect of round.

To address this concern, we conduct the same analyses but include only participants who completed all four rounds of the Tournament. The round effect remains. As before, the par-birdie discrepancy in accuracy diminishes by half between the first and the fourth round. 
The finding that the round of play moderates our effect is interesting for two reasons. First, this finding demonstrates that the discrepancy in accuracy between birdie and par putts is not automatic and argues against alternative accounts. For example, none of the following alternative explanations can account for why the discrepancy would diminish across rounds: birdie putts are more difficult than par putts because they start from a more precarious position on the green, birdie putts are more difficult than par putts because they follow a longer approach shot, or birdie putts are more difficult than par putts because players learn more information prior to taking a par shot.

Second, the finding that the round of play moderates our effect is interesting because it is consistent with our reference point story. In the first round, the reference point of par is likely to be very salient for golfers. By the fourth round, however, other reference points such as the scores of other golfers are likely to be more salient. These competing reference points are likely to diminish the influence of par on performance. In fact, some golfers colloquially refer to Round 3 of PGA Tournaments (typically Saturday) as "moving day." After a third of the players have been cut, golfers may shift their focus to their peer's performance as they try to change their rank or "move."

\section{E. Differences in Risk Aversion}

According to Prospect Theory, economic agents are risk averse in the domain of gains and risk seeking in the domain of losses. If golfers narrowly bracket on individual holes and adopt par as their reference point, we would expect golfers to be more risk averse when hitting birdie and eagle putts than they are when they hit par, bogey, and double bogey putts.

When putting, golfers balance two objectives. One objective is to hit the ball into the hole. The second objective is to limit the difficulty of a follow-on shot should they miss their putt. On average, conditional on missing the putt, golfers hit the ball 15-25 inches past the hole. Risk averse putts are putts that are hit short. Risk averse putts sacrifice the likelihood of hitting the ball into the hole to limit the difficulty of a follow-on shot. Within our framework, we expect birdie and eagle putts to be hit less hard than par, bogey, and double bogey putts.

Consistent with our thesis, conditional on missing the putt, golfers hit birdie and eagle putts significantly less hard than they hit par, bogey, and double bogey putts. We report results from OLS regressions in Table 6 in columns 1 and 2. These regressions include missed putts and predict the probability of leaving a putt short of the hole as a function of the type of putt attempted. Eagle putts, on average, are hit 0.80 inches less hard than equally distanced par putts, and birdie putts are hit 0.19 inches less hard than par putts. Surprisingly, bogey and double bogey putts are also hit softer than par putts, although there are very few missed bogey and double bogey putts. In this analysis, the standard errors of these estimates are very large.

In Table 6 in column 2, we also report the probability that the ball will be hit short of the hole. Consistent with our thesis, eagle and birdie putts are both significantly more likely to be hit short of the hole than par putts. In Table 6 in columns 3 and 4, we provide similar results to those we report in columns 1 and 2, but we restrict the sample to putts longer than 270 inches (the average putt distance for missed putts). 
Table 6-The Effect of Different Shot Values on Risk Aversion

\begin{tabular}{|c|c|c|c|c|c|}
\hline & \multicolumn{5}{|c|}{ Ordinary least squares } \\
\hline & \multicolumn{2}{|c|}{$\begin{array}{l}\text { All missed } \\
\text { putts }\end{array}$} & \multicolumn{2}{|c|}{$\begin{array}{l}\text { Missed putts longer } \\
\text { than } 270 \text { inches }\end{array}$} & \multirow{2}{*}{$\begin{array}{c}\text { All missed } \\
\text { putts } \\
\text { Make next putt } \\
\text { (5) }\end{array}$} \\
\hline & $\begin{array}{l}\text { Putt length } \\
\text { (1) }\end{array}$ & $\begin{array}{l}\text { Left short } \\
\text { (2) }\end{array}$ & $\begin{array}{l}\text { Putt length } \\
\text { (3) }\end{array}$ & $\begin{array}{l}\text { Left short } \\
\text { (4) }\end{array}$ & \\
\hline Putt for eagle & $\begin{array}{l}-0.80 * * \\
(0.32)\end{array}$ & $\begin{array}{l}0.013 * * * \\
(0.003)\end{array}$ & $\begin{array}{l}-2.44 * * * \\
(0.56)\end{array}$ & $\begin{array}{l}0.032 * * * \\
(0.006)\end{array}$ & $\begin{array}{c}-0.003 \\
(0.002)\end{array}$ \\
\hline Putt for birdie & $\begin{array}{c}-\mathbf{0 . 1 9} * * \\
(\mathbf{0 . 0 8})\end{array}$ & $\begin{array}{l}\text { 0.003*** } \\
(\mathbf{0 . 0 0 1 )}\end{array}$ & $\begin{array}{l}-1.59 * * * \\
(0.27)\end{array}$ & $\begin{array}{l}\text { 0.019*** } \\
(\mathbf{0 . 0 0 3})\end{array}$ & $\begin{array}{l}\text { 0.001** } \\
(\mathbf{0 . 0 0 1})\end{array}$ \\
\hline Putt for bogey & $\begin{array}{c}-0.365 \\
(0.19)\end{array}$ & $\begin{array}{l}0.007 * * * \\
(0.003)\end{array}$ & $\begin{array}{c}0.65 \\
(0.72)\end{array}$ & $\begin{array}{c}0.000 \\
(0.008)\end{array}$ & $\begin{array}{c}-0.003 \\
(0.001)\end{array}$ \\
\hline Putt for double bogey & $\begin{array}{c}-0.053 \\
(0.29)\end{array}$ & $\begin{array}{c}0.008 \\
(0.004)\end{array}$ & $\begin{array}{c}0.41 \\
(0.95)\end{array}$ & $\begin{array}{c}-0.001 \\
(0.011)\end{array}$ & $\begin{array}{l}- \\
-\end{array}$ \\
\hline $\begin{array}{l}\text { Putt distance: seventh-order } \\
\text { polynomial }\end{array}$ & $\mathrm{X}$ & $\mathrm{X}$ & $\mathrm{X}$ & $\mathrm{X}$ & $\mathrm{X}$ \\
\hline Player fixed effects & $\mathrm{X}$ & $\mathrm{X}$ & $\mathrm{X}$ & $\mathrm{X}$ & $\mathrm{X}$ \\
\hline Previous-putts-on-green effects & $X$ & $X$ & $\mathrm{X}$ & $X$ & $\mathrm{X}$ \\
\hline Tournament-round-hole effects & $\mathrm{X}$ & $\mathrm{X}$ & $X$ & $X$ & $\mathrm{X}$ \\
\hline$R^{2}$ & 0.968 & 0.169 & 0.918 & 0.127 & 0.095 \\
\hline Observations & 986,963 & 986,963 & 406,942 & 406,942 & 977,500 \\
\hline
\end{tabular}

Notes: This table reports estimates and robust standard errors for the differential success rate of putts of different shot values (par, birdie, etc.) using OLS. Columns 1 and 2 report the estimates of shot value on putt length and laying up short of the hole using all missed putts in the data. Columns 3 and 4 provide similar estimates but for putts attempted at a distance of more than 270 inches (the average distance of a missed putt). Column 5 reports the impact of shot value on the probability of making the next putt (conditional on missing the current putt).

*** Significant at the 1 percent level.

** Significant at the 5 percent level.

These estimates, which are larger than those found in columns 1 and 2, suggest that the effects are strongest for long putts. 15

In Figure 3, we depict where missed par and birdie putts stop on the green with respect to the hole. We normalize each putt as if it were lined up with the hole from the left side of the x-axis. We divide the green around the hole into a series of 12 inch $\times 12$ inch boxes. We then run separate OLS regressions for each box. The dependent variable is a binary outcome equal to one if the missed putt stopped in the box. The numbers represented in each box are the coefficient of birdie putts from these regressions. Positive numbers indicate that birdie putts are more likely to stop in the box than par putts. Negative numbers indicate that par putts are more likely to stop in the box than birdie putts.

In Figure 3, the positive numbers in front of the hole illustrate that birdie putts are more likely to stop in front of the hole, and that par putts are more likely to stop behind the hole. We report similar analyses in Figure 3, panel B. In this figure, we restrict the sample to missed putts attempted from more than 270 inches (the average distance of a missed putt). As before, this figure demonstrates that birdie putts are hit less hard than par putts.

Is risk aversion helpful? Birdie putts are hit less hard than par putts. Though birdie putts are less likely than par putts to land in the hole, softer hits make the follow-on shots after missed birdie putts easier than follow-on shots after missed par putts.

\footnotetext{
${ }^{15}$ For very short putts, putts less than 200 inches, we find no differences. Notably, the risk aversion account cannot explain the entire par-birdie accuracy gap.
} 
Panel A. All missed putts

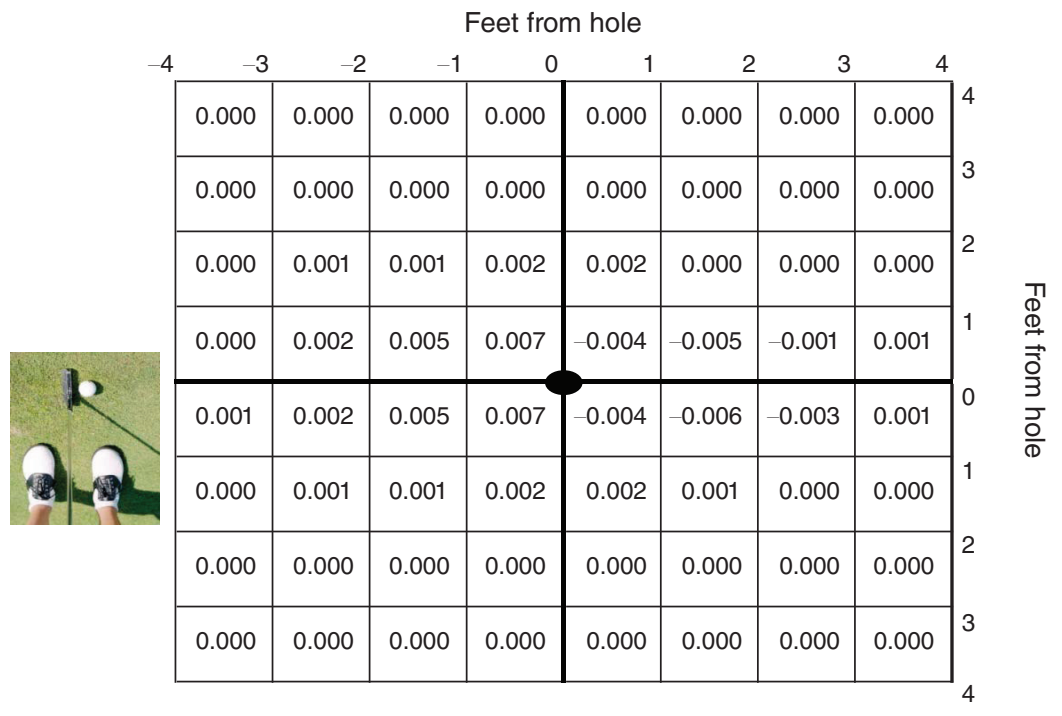

Panel B. Missed putts taken from more than 270 inches

Feet from hole

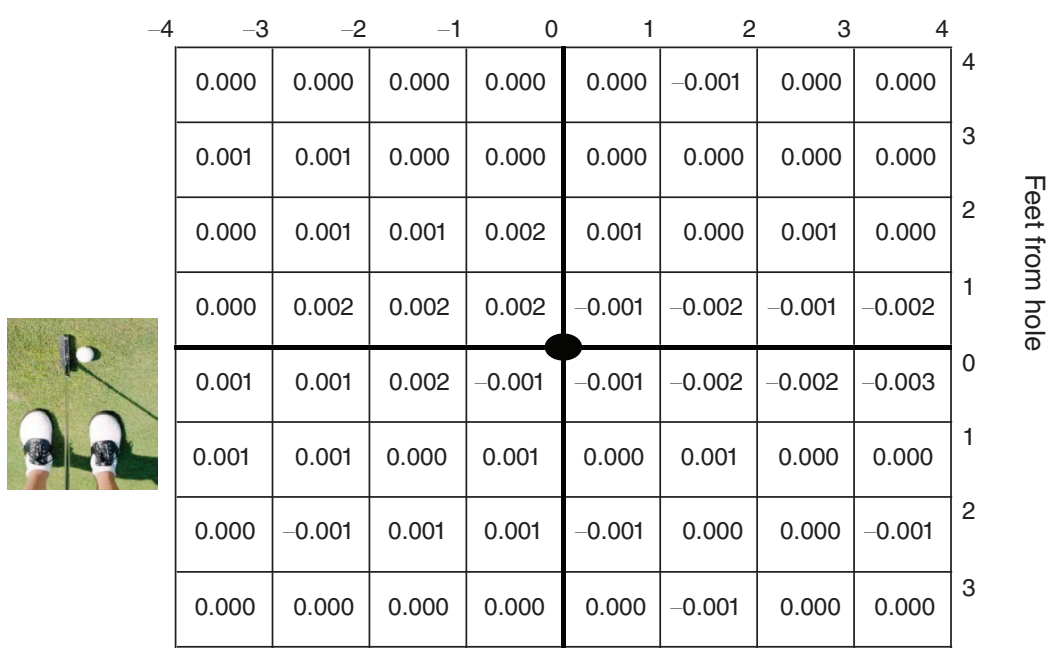

Figure 3

Notes: This figure provides a graphical illustration of where each missed putt (Figure 3a $)$ and each missed putt taken from more than 220 inches away, a distance greater than the average missed putt length (Figure $3 \mathrm{~b}$ ) came to a rest. Each putt is oriented so as to be taken from the left side of the $\mathrm{x}$ axis and the hole at the origin. We conducted a separate regression (with controls) for each 12 inch $\times 12$ inch box with a dummy dependent variable indicating whether the missed putt came to rest in the box. The number in each box is the coefficient on a birdie putt indicator. Positive (negative) coefficients indicate that birdie putts are more (less) likely to come to rest in the box than par putts.

In Table 4 in column 5, we report results predicting whether or not the follow-on shot landed in the hole conditional on missing the current putt. Results from this analysis indicate that the softer birdie putts do indeed improve the probability of making a follow-up shot. However, the size of this effect ( 0.1 percent) is only marginally significant and is overwhelmed by the decreased probability of making the 
initial putt. That is, the increased probability of making a follow-up shot by hitting a birdie putt softly does not come close to compensating for the loss of accuracy in hitting birdie putts. 16

This finding is consistent with other analyses not reported, such as analyses estimating the total number of strokes required to finish the hole following a par or birdie putt. The results are nearly identical when looking at total future strokes, because the advantage to laying it up short is overwhelmed by the decrease in accuracy of the original putt.

While golfers are more risk averse when putting for birdie, this aversion cannot explain the entire difference in putt success between birdie and par putts that we find. Birdie putts are more likely to be laid up short of the hole, but they also are significantly more likely to miss the hole to the left or right. ${ }^{17}$ Because of these leftright mistakes, the distance of follow-up shots from missed birdie putts is similar to the distance from missed par putts. Thus, birdie putts are missed more often due to both risk aversion as well as left-right mistakes.

\section{F. Köszegi-Rabin Reference Points}

In our conceptual framework and in our analyses, we have assumed that golfers making reference dependent choices adopt par as their point of reference. In recent theoretical work, Kószegi and Rabin (2006) suggest that rational expectations might serve as the point of reference for reference-dependent choices. A recent empirical study supports this idea. Crawford and Meng (2008) found that by allowing rational expectations to inform reference points for hours worked and income earned, they were able to fit a model of cabdrivers' labor supply decisions with greater accuracy (Camerer et al. 1997; Henry S. Farber 2005). Farber (2008) and Doran (2008) also study cabdriver labor supply and also make significant contributions to understanding reference point adaptation. Farber (2008) allows reference points to be different across people but treats the income reference points as latent variables (as opposed to assigning reference points based on rational expectations). Doran (2008) finds that cabdrivers who display reference-dependent preferences did not change their hours worked following an exogenous permanent wage increase. This finding is consistent with Köszegi-Rabin's (2006) model of reference point adaptation.

Although par is likely to be a salient reference point, professional golfers may develop expectations for their performance that are different from par. For example, on an easy par-five hole an expert golfer may expect to complete the hole with four shots. In this case, four (rather than five) shots may serve as the reference point.

We consider a rational expectations approach for reference point adoption. In our next set of analyses, we use the average score on each hole by the entire field of golfers, rather than par, as the reference point. In Figure 4, we depict how this rational expectations approach changes our predictions. In Figure 4a, we illustrate

\footnotetext{
${ }^{16}$ Although players hit birdie putts less hard, these shots also have greater left-right variance. As a result, followup putts after a birdie putt are from a similar distance as follow-up putts after a par putt.

${ }^{17}$ This can be shown by calculating the angle (using the law of cosines) between the starting and ending position of the ball relative to the hole-where an angle of zero indicates that the ball ended along the straight line between the starting position and the hole. Analyses indicate that this angle (left/right mistake) is significantly larger for birdie putts than for par putts.
} 
Panel A. Constant reference points

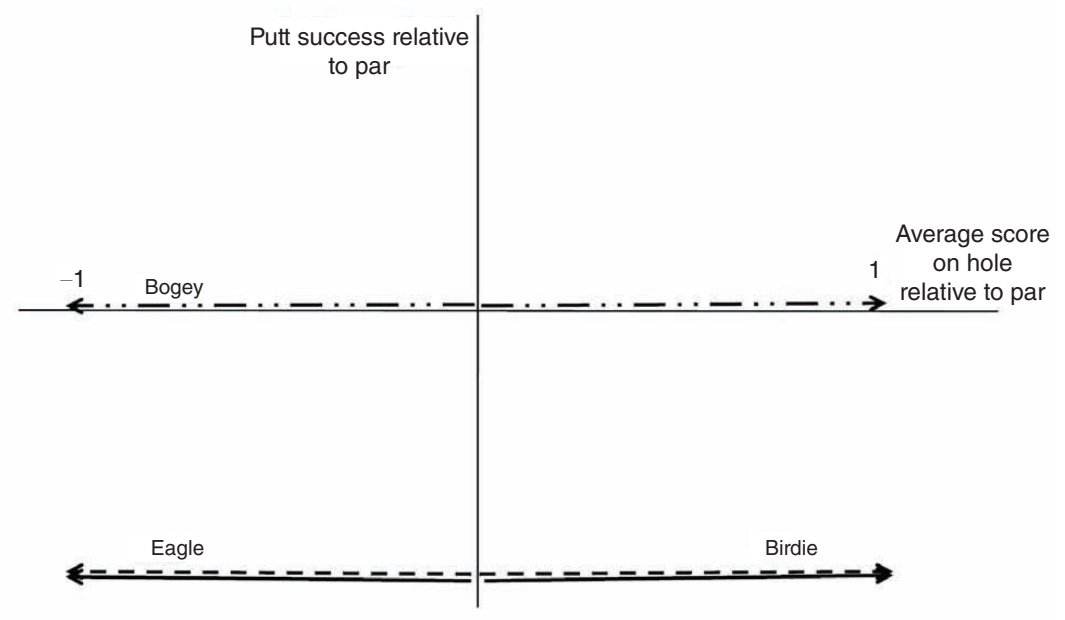

Panel B. Reference points based on rational expectations

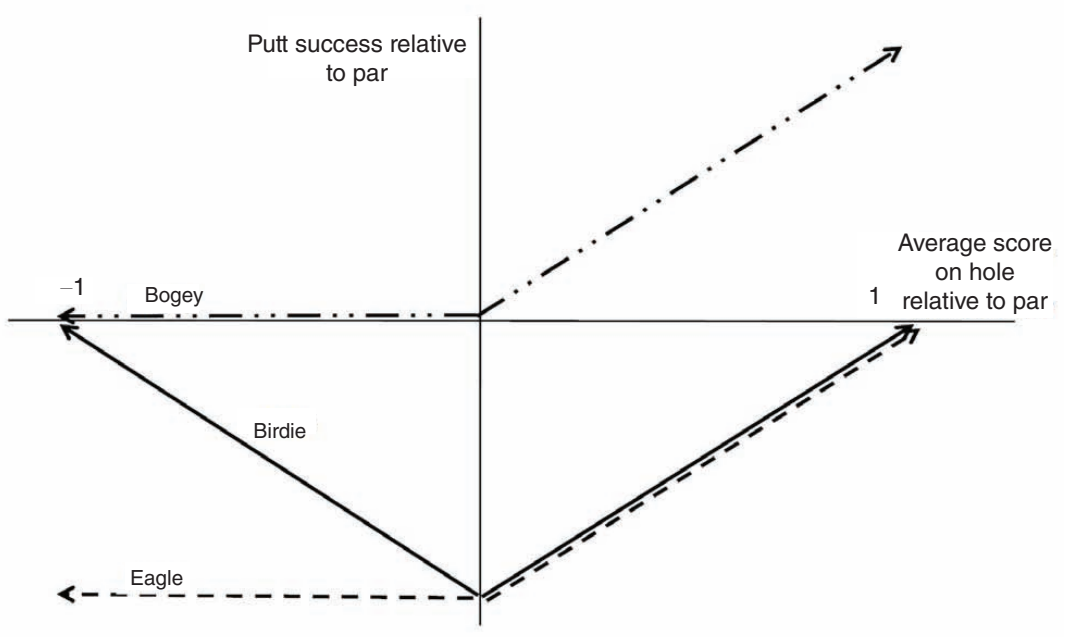

Figure 4

Notes: This figure illustrates the theoretical predictions for putt success for different shot values relative to par, assuming par as the reference point (panel A) and assuming rational expectations equal to the empirical score on each hole as the reference point (panel B).

how loss aversion influences putt accuracy if golfers adopt par as the reference point. In Figure 4b, we illustrate how loss aversion influences putt accuracy if golfers adopt the average score on each hole (our proxy for rational expectations) as the reference point. ${ }^{\text {I1 }}$ We develop predictions for eagle, birdie, par, bogey, and double bogey putts, but we focus particular attention on the contrast between birdie and par putts.

\footnotetext{
18 Figure 4 derives from Prospect Theory with no diminishing sensitivity. Depending on the degree of diminishing sensitivity, Figures 4A and 4B would both change in predictable ways. For example, diminishing sensitivity in the gain domain only (similar to what we find in our results) would cause the following changes to Figure 4B: the eagle line would shift downward and become concave to the origin to the left of 0 and convex to the origin to the right of 0 , the birdie line would become convex to the origin to the left of zero and would remain under the $\mathrm{x}$-axis (even at 1) to the right of zero, and the bogey line would grow more steeply as it approached 1 .
} 
If the average score on a hole is the same as par, our predictions in Figure 4 panel $\mathrm{A}$ and panel B are the same. We expect golfers to be less likely to make birdie and eagle putts than par, bogey, and double bogey putts. In this case, we expect golfers to be more accurate hitting their par putts than their birdie putts.

If the average score on a hole is one over par (a difficult hole), then golfers who adopt rational expectations will expect their bogey putt to be the putt that finishes the hole. In this case, golfers will perceive par, birdie, and eagle putts to be in the "gain domain," and we expect golfers to be less accurate hitting these putts than otherwise similar bogey and double bogey putts. In this case, we expect par and birdie putts to be hit similarly.

Analogously, if the average score on a hole is one under par (an easy hole), then golfers who adopt rational expectations will expect their birdie putt to be the putt that finishes the hole. In this case, golfers will perceive only eagle putts to be in the gain domain, and we expect golfers to hit their eagle putts less accurately than otherwise similar birdie, par, bogey, and double bogey putts. In this case, we expect par and birdie putts to be hit similarly.

Our key prediction in testing the Konszegi and Rabin (2006) framework is the "V shape" pattern depicted in Figure 4 panel B representing the relationship between the relative accuracy of par and birdie putts. When average scores on a hole are either one above or one below par, the expectations-as-reference-points model predicts that golfers will hit their par and birdie putts similarly. When average scores on a hole equal par, the expectations-as-reference-points model predicts that golfers will hit their par putts more accurately than they hit their birdie putts.

To test these predictions, we divided the data into quintiles according to the difficulty of the hole relative to par. The first quintile includes holes with average scores much lower than par (very easy holes); the fifth quintile includes holes with average scores much higher than par (very difficult holes). The variation in hole difficulty, however, is limited. Compared to par, the average hole scores for the first and fifth quintiles are -0.30 and 0.33 , respectively. The coefficient and standard errors from a logit regression for each quintile are presented in the Web Appendix and the coefficients are presented in Figure 5. 19

Consistent with the expectations-as-reference-points predictions, informed by Kôszegi and Rabin (2006), we find that the accuracy difference between par and birdie putts diminishes for difficult holes; the relative accuracy declines from 2.9 percent on moderately difficult holes (holes with average scores equal to par) to 2.3 percent for difficult holes (holes with average scores equal to 0.3 strokes more than par), $\mathrm{p}<0.001$. However, the accuracy difference between par and birdie putts does not diminish for easy holes; the accuracy difference does not decline from moderately difficult holes (holes with average scores equal to par) to difficult holes (holes with average scores equal to -0.3 strokes less than par).

The expectations-as-reference-points model predicts that bogey putts will be hit as accurately as par putts on moderate and easy holes (holes with average scores equal to or lower than par), but more accurately than par putts on difficult holes

\footnotetext{
${ }^{19}$ For these regressions, we use logit rather than OLS, because logit regression allows the shot value coefficients to vary with distance. This enables the coefficients to reflect more accurately the changes in distance across quintiles.
} 


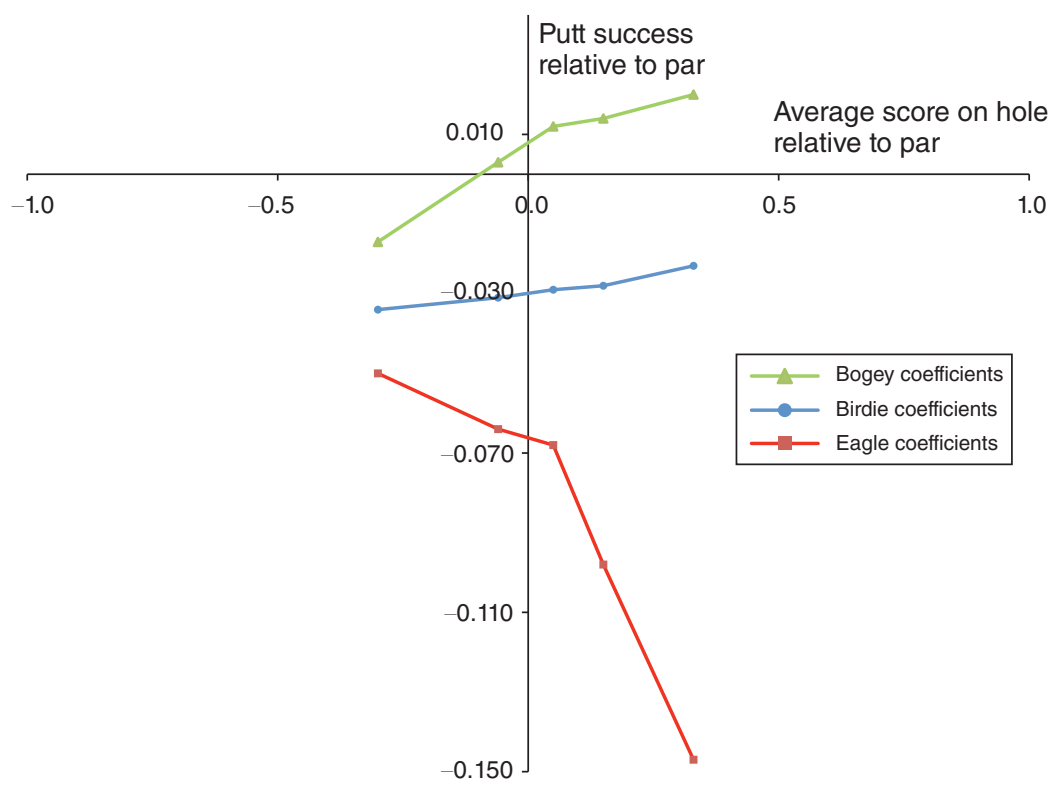

FIGURE 5

Note: This figure graphs the relative putt accuracy for birdie, eagle, and bogey compared to par for each of five quintiles characterized by the difficulty of the hole relative to par.

(holes with average scores higher than par). Our results do not uniformly support these predictions, but we do find that bogey putts are hit relatively more accurately than par putts as hole difficulty increases.

The pattern of results we observe for eagle putts is not consistent with the expectations-as-reference-points predictions. Eagle putts, however, comprise only 1.3 percent of the putts in our data, and within our quintile analyses, the standard errors of the estimates we plot in Figure 6 are very large. For example, the coefficient for eagle putts in the fifth quintile, which is inconsistent with the expectations-asreference-points prediction, is only marginally different from par (the expectationsas-reference-points prediction).

By accounting for endogenized reference points derived from rational expectations, we increase the predictive validity of our models. Taken together, our results offer some support for the expectations-as-reference-points predictions.

\section{G. Heterogeneity in Loss Aversion}

We next consider heterogeneity across players. We consider individual differences, and we explore the possibility that the most experienced golfers exhibit less loss aversion than other players.

For each golfer, we measure the accuracy difference between par and birdie putts. We measure this effect with the birdie coefficient produced by an OLS model that uses par as the baseline (see Table 3, column 1).

On average, golfers make their birdie putts 3.6 percentage points less often than they make otherwise similar par putts. We find, however, substantial variation across 
Panel A. Histogram of birdie coefficients

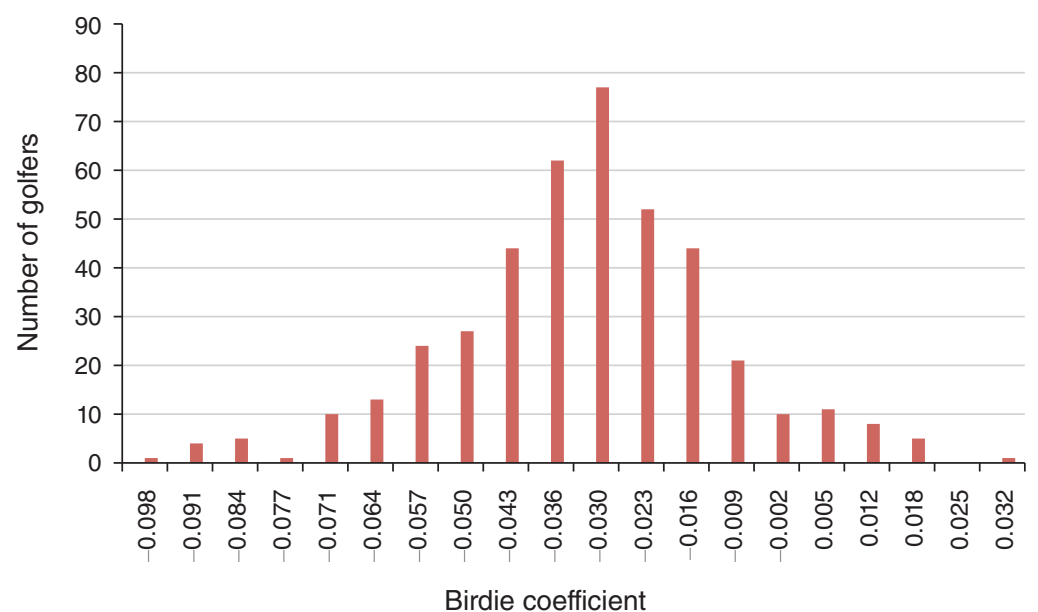

Panel B. Birdie coefficient and PGA rank

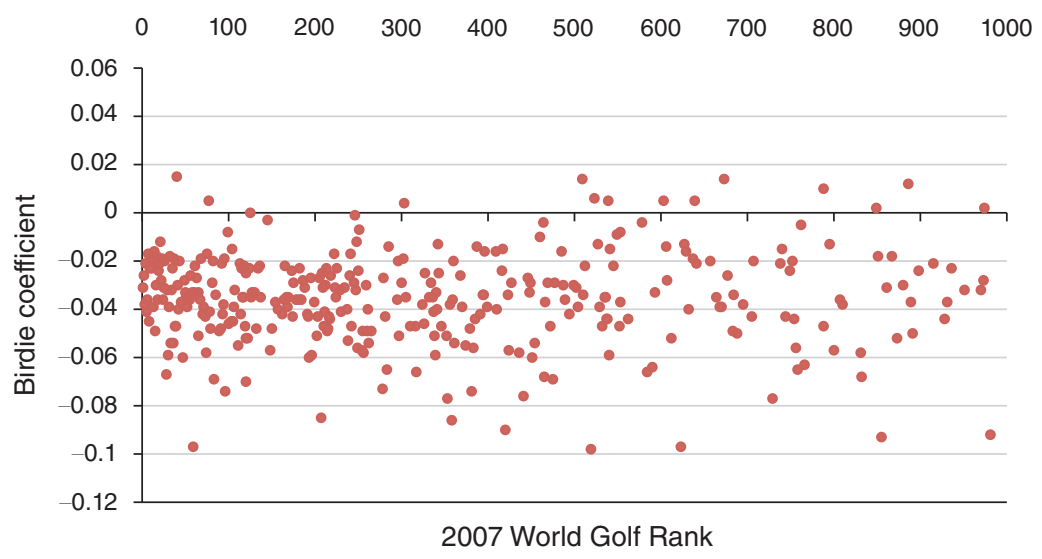

Figure 6

Notes: Figure 6A plots a histogram of the relative accuracy of birdie putts compared to par putts using our baseline specification (column 1 of Table 3) for each of the 421 golfers in our dataset. Figure $6 \mathrm{~B}$ plots the relative accuracy of birdie compared to par putts for each golfer by each golfer's 2007 World Golf Rank.

players. We depict this variation in a histogram in Figure 6 panel A, and we find that the variation in loss aversion across players is significant (in a chi-squared test, $\mathrm{p}<0.001)$. Consistent with loss aversion, the large majority of players (94 percent) have negative point estimates.

Prior work has found that experience can eliminate judgment biases (e.g., List 2003, 2004), and with our data we consider the possibility that expertise mitigates loss aversion. We use each player's 2007 World Golf Rank as a measure of expertise. In Figure 6 panel B, we present a scatter plot of each golfer's 2007 World Golf Rank and his relative accuracy coefficient for birdie. We find no significant relationship between a golfer's overall rank and his tendency to miss birdie relative to par putts $(\mathrm{p}=0.90)$. 
Table 7-Understanding the Costs of Missing Birdie Putts

\begin{tabular}{|c|c|c|c|c|c|c|}
\hline $\begin{array}{l}2007 \\
\text { Rank } \\
\end{array}$ & Golfer & $\begin{array}{c}\text { Tournaments } \\
\text { played }\end{array}$ & $\begin{array}{l}\text { Scoring } \\
\text { average } \\
\text { (72 holes) } \\
\end{array}$ & $\begin{array}{c}\text { Tournament } \\
\text { earnings } \\
(2007) \\
\end{array}$ & $\begin{array}{c}\text { Additional } \\
\text { earnings if scored } \\
1 \text { stroke better }\end{array}$ & $\begin{array}{c}\% \text { earnings } \\
\text { increase if scored } \\
1 \text { stroke better } \\
\end{array}$ \\
\hline 1 & Tiger Woods & 16 & 69.1 & $\$ 10,867,052$ & $\$ 945,532$ & 8.70 \\
\hline 2 & Vijay Singh & 27 & 70.39 & $\$ 4,728,376$ & $\$ 584,550$ & 12.36 \\
\hline 3 & Jim Furyk & 23 & 70.21 & $\$ 4,154,046$ & $\$ 1,530,232$ & 36.84 \\
\hline 4 & Phil Mickelson & 22 & 70.39 & $\$ 5,819,988$ & $\$ 659,750$ & 11.34 \\
\hline 5 & K. J. Choi & 25 & 70.4 & $\$ 4,587,859$ & $\$ 362,450$ & 7.90 \\
\hline 6 & Rory Sabbatini & 23 & 70.49 & $\$ 4,550,040$ & $\$ 902,567$ & 19.84 \\
\hline 7 & Zach Johnson & 23 & 70.95 & $\$ 3,922,338$ & $\$ 347,000$ & 8.85 \\
\hline 8 & Charles Howell III & 26 & 71.47 & $\$ 2,832,091$ & $\$ 374,500$ & 13.22 \\
\hline 9 & Brandt Snedeker & 29 & 70.5 & $\$ 2,836,643$ & $\$ 393,650$ & 13.88 \\
\hline 10 & Adam Scott & 19 & 70.96 & $\$ 3,413,185$ & $\$ 221,400$ & 6.49 \\
\hline 11 & Scott Verplank & 23 & 70.56 & $\$ 3,114,289$ & $\$ 490,750$ & 15.76 \\
\hline 12 & Steve Stricker & 23 & 70.19 & $\$ 4,663,077$ & $\$ 1,077,000$ & 23.10 \\
\hline 13 & Sergio Garcia & 19 & 70.45 & $\$ 3,721,185$ & $\$ 784,807$ & 21.09 \\
\hline 14 & Woody Austin & 27 & 70.84 & $\$ 2,887,596$ & $\$ 399,066$ & 13.82 \\
\hline 15 & Hunter Mahan & 27 & 70.78 & $\$ 2,858,995$ & $\$ 339,533$ & 11.88 \\
\hline 16 & John Rollins & 29 & 70.97 & $\$ 2,488,891$ & $\$ 1,005,300$ & 40.39 \\
\hline 17 & Boo Weekley & 29 & 70.95 & $\$ 2,613,211$ & $\$ 883,633$ & 33.81 \\
\hline 18 & Aaron Baddeley & 23 & 70.96 & $\$ 3,441,119$ & $\$ 277,040$ & 8.05 \\
\hline 19 & Ernie Els & 16 & 70.5 & $\$ 2,705,715$ & $\$ 734,633$ & 27.15 \\
\hline 20 & Mark Calcavecchia & 28 & 71.11 & $\$ 2,993,332$ & $\$ 504,533$ & 16.86 \\
\hline Average & & 23.85 & 70.6 & $\$ 3,959,951$ & $\$ 640,896$ & 17.6 \\
\hline
\end{tabular}

Notes: We obtained these data for the top 20 ranked golfers from golf.com. (Golf. 2007. "Back on Track." March 23. http://www.golf.com/golf/tours_news/article/0,28136,1602656,00.html.) Along with their ranks, names, tournaments played, average score, and annual tournament earnings, the table provides the additional earnings each player would have earned had he increased his score by one stroke per tournament relative to the rest of the golfers.

\section{H. Size of the Effects}

To understand the magnitude of the effects we observe, we consider how hitting birdie putts as accurately as otherwise similar par putts would change expected Tournament winnings. On average, golfers who play all four rounds in our sample attempt 45.1 birdie putts in each Tournament. Using our most conservative estimates, we calculate that if golfers hit each of their birdie putts as accurately as they hit otherwise similar par putts, their Tournament score would improve by more than one stroke per Tournament.

In professional golf, improving a score by one stroke is substantial. In Table 7, for each of the top 20 golfers in 2007, we list the number of 2007 Tournaments in which he participated, his average score across these Tournaments, and his Tournament earnings for 2007. On average, the top 20 golfers earned nearly $\$ 4$ million in Tournament earnings alone. ${ }^{\text {[a }}$ For each player, we created a counterfactual and calculated the additional amount he would have earned had he improved his score by one stroke in each of the Tournaments in which he participated (assuming that other players' scores remained unchanged). On average, these golfers would have earned an additional $\$ 640,000$ (17.6 percent). These results offer insight into the importance of our effect,

\footnotetext{
${ }^{20}$ For the top golfers, Tournament earnings are likely to underestimate the total value they receive from doing well in golf. For example, due mainly to endorsements, Forbes (2006. "Not as Rich as You'd Think." Forbes, September 18. http://www.forbes.com/2006/09/15/cx_aolarpslide.html) declared Tiger Woods' net worth to be $\$ 500$ million_far more than his approximately \$83 million in career Tournament earnings as of the end of 2008.
} 
but these results should be interpreted with care. Although the top golfers in our dataset would earn substantially more money if they could hit their birdie putts like their par putts, concentration and effort may be limited resources. Quite possibly, golfers may be unable to hit all of their putts with equal accuracy.

\section{Discussion and Conclusion}

Our results demonstrate that loss aversion, a fundamental bias, continues to persist in a highly competitive market. We find that experienced agents systematically exhibit this bias and that it is not only pervasive, but costly.

In our study, we document loss aversion in professional golf. We analyze detailed data from the PGA Tour, and we demonstrate that professional golfers hit birdie putts less accurately than they hit otherwise similar par putts. We consider a number of competing explanations including differences in position on the green, individual differences, and learning. We find that none of these explanations can account for the pattern of results we observe, and we demonstrate that even the very best golfers-including Tiger Woods — exhibit this bias.

Interestingly, the bias we observe is moderated by round. As the Tournament progresses, the accuracy gap between par and birdie putts diminishes but is not extinguished. This finding implies that the accuracy gap derives from a psychological rather than a mechanical process.

Our findings are consistent with Prospect Theory (Kahneman and Tversky 1979). Rather than broadly bracketing across the 72 holes in a Tournament, players narrowly bracket and adopt the salient reference point of par within each hole. Although professional golfers should strive to hit each putt as accurately as possible, golfers hit birdie putts (in the domain of "gains") less accurately and less hard than they hit par putts (in the domain of "losses").

We also consider and find evidence to suggest that golfers use rational expectations to set reference points (Köszegi and Rabin 2006). We use average performance on holes to gauge hole difficulty, and, consistent with Köszegi and Rabin (2006), we find that the accuracy gap between par and birdie putts diminishes for very difficult holes and that the gap between par and bogey putts widens for very difficult holes.

Although we find persistent bias among experienced professionals in a highstakes setting, we cannot directly generalize our findings in golf to other domains, such as financial advising, real estate, and public policy. Our results, however, are suggestive. If Tiger Woods exhibits loss aversion when he plays golf on the PGA Tour, judgment biases may be more pervasive than prior research suggests.

\section{REFERENCES}

-Ariely, Dan, Uri Gneezy, George Loewenstein, and Nina Mazar. 2009. "Large Stakes and Big Mistakes." Review of Economic Studies, 76(2): 451-69.

Barber, Brad M., and Terrance Odean. 2001. "Boys Will Be Boys: Gender, Overconfidence, and Common Stock Investment." Quarterly Journal of Economics, 116(1): 261-92.

Beilock, Sian. 2008. "Math Performance in Stressful Situations." Current Directions in Psychological Science, 17(5): 339-43.

Beilock, Sian, James Afremow, Amy Rabe, and Thomas Carr. 2001. "Don't Miss! The Debilitating Effects of Suppressive Imagery on Golf Putting Performance.” Journal of Sport \& Exercise Psychology, 23(3): 200-21. 
Beilock, Sian, Bennett Bertenthal, Annette McCoy, and Thomas Carr. 2004. "Haste Does Not Always Make Waste: Expertise, Direction of Attention, and Speed versus Accuracy in Performing Sensorimotor Skills." Psychonomic Bulletin \& Review, 11(2): 373-79.

Benartzi, Shlomo, and Richard H. Thaler. 1995. "Myopic Loss Aversion and the Equity Premium Puzzle." Quarterly Journal of Economics, 110(1): 73-92.

Berger, Jonah, and Devin Pope. 2009. "Can Losing Lead to Winning? Competition, Motivation and Performance.” http://marketing.wharton.upenn.edu/documents/research/Losing_and_Winning.pdf.

Brown, Jennifer. 2007. "Quitters Never Win: The (Adverse) Incentive Effects of Competing with Superstars." https://europealumni.kellogg.northwestern.edu/mgmtstrategy/deptinfo/seminars/ brown011608.pdf.

Camerer, Colin F. 2000. "Prospect Theory in the Wild: Evidence from the Field." In Choices, Values, and Frames, ed. Daniel Kahneman, and Amos Tversky, 288-300. New York: Cambridge University Press.

Camerer, Colin F., and Dan Lovallo. 1999. "Overconfidence and Excess Entry: An Experimental Approach." American Economic Review, 89(1): 306-18.

Camerer, Colin F., George Loewenstein, and Matthew Rabin, ed. 2004. Advances in Behavioral Economics. Princeton, NJ: Princeton University Press.

Camerer, Colin F., Linda Babcock, George Loewenstein, and Richard H. Thaler. 1997. "Labor Supply of New York City Cabdrivers: One Day at a Time." Quarterly Journal of Economics, 112(2): 407-41.

Cotton, Christopher, and Joseph Price. 2006. "The Hot Hand, Competitive Experience, and Performance Differences by Gender." Munich Personal Research Papers in Economics Archive Working Paper 1843.

Crawford, Vincent, and Juanjuan Meng. 2008. "New York City Cabdrivers' Labor Supply Revisited: Reference-Dependence Preferences with Rational-Expectations Targets for Hours and Income." University of California at San Diego Department of Economics Working Paper 2008-03.

DellaVigna, Stefano. 2009. "Psychology and Economics: Evidence from the Field." Journal of Economic Literature, 47(2): 315-72.

Doran, Kirk. 2008. "References Points, Expectations, and Heterogeneous Daily Labor Supply." Unpublished.

Ehrenberg, Ronald G., and Michael L. Bognanno. 1990. “Do Tournaments Have Incentive Effects?" Journal of Political Economy, 98(6): 1307-24.

Farber, Henry S. 2005. "Is Tomorrow Another Day? The Labor Supply of New York City Cabdrivers." Journal of Political Economy, 113(1): 46-82.

Farber, Henry S. 2008. "Reference-Dependent Preferences and Labor Supply: The Case of New York City Taxi Drivers." American Economic Review, 98(3): 1069-82.

Fehr, Ernst, and Lorenz Goette. 2007. "Do Workers Work More If Wages Are High? Evidence from a Randomized Field Experiment." American Economic Review, 97(1): 298-317.

Fershtman, Chaim, and Uri Gneezy. 2007. "Quitting.” Unpublished.

Genesove, David, and Christopher Mayer. 2001. "Loss Aversion and Seller Behavior: Evidence from the Housing Market.” Quarterly Journal of Economics, 116(4): 1233-60.

Gneezy, Uri, and Jan Potters. 1997. "An Experiment on Risk Taking and Evaluation Periods." Quarterly Journal of Economics, 112(2): 631-45.

Guryan, Jonathan, Kory Kroft, and Matthew J. Notowidigdo. 2009. "Peer Effects in the Workplace: Evidence from Random Groupings in Professional Golf Tournaments." American Economic Journal: Applied Economics, 1(4): 34-68.

Haigh, Michael S., and John A. List. 2005. "Do Professional Traders Exhibit Myopic Loss Aversion? An Experimental Analysis." Journal of Finance, 60(1): 523-34.

Hart, Sergiu. 2005. "An Interview with Robert Aumann.” Macroeconomic Dynamics, 9(5): 683-740.

Kahneman, Daniel, and Amos Tversky. 1979. "Prospect Theory: An Analysis of Decision under Risk." Econometrica, 47(2): 263-91.

Koriat, Asher, Sarah Lichtenstein, and Baruch Fischhoff. 1980. "Reasons for Confidence." Journal of Experimental Psychology: Human Learning and Memory, 6(2): 107-18.

-Köszegi, Botond, and Matthew Rabin. 2006. "A Model of Reference-Dependent Preferences." Quarterly Journal of Economics, 121(4): 1133-65.

Levitt, Steven D., and John A. List. 2008. "Homo Economicus Evolves.” Science, 319(5865): 909-10.

Lichtenstein, Sarah, Baruch Fischhoff, and Lawrence Phillips. 1982. "Callibration of Probabilities: The State of the Art to 1980." In Judgment under Uncertainty: Heuristics and Biases, ed. Daniel Kahneman, Paul Slovic, and Amos Tversky. New York: Cambridge University Press.

List, John A. 2002. "Preference Reversals of a Different Kind: The "More Is Less" Phenomenon." American Economic Review, 92(5): 1636-43.

List, John A. 2003. "Does Market Experience Eliminate Market Anomalies?" Quarterly Journal of Economics, 118(1): 41-71. 
-List, John A. 2004. "Neoclassical Theory versus Prospect Theory: Evidence from the Marketplace." Econometrica, 72(2): 615-25.

-Mas, Alexandre. 2006. "Pay, Reference Points, and Police Performance." Quarterly Journal of Economics, 121(3): 783-821.

McCarthy, Julie, and Richard Goffin. 2004. "Measuring Job Interview Anxiety: Beyond Weak Knees and Sweaty Palms." Personnel Psychology, 57(3): 607-37.

Odean, Terrance. 1998. “Are Investors Reluctant to Realize Their Losses?” Journal of Finance, 53(5): 1775-98.

- Read, Daniel, George Loewenstein, and Matthew Rabin. 1999. "Choice Bracketing." Journal of Risk and Uncertainty, 19(1-3): 171-97.

Sarason, Irwin. 1984. "Stress, Anxiety, and Cognitive Interference: Reactions to Tests." Journal of Personality and Social Psychology, 46(4): 929-38.

- Thaler, Richard H., Amos Tversky, Daniel Kahneman, and Alan Schwartz. 1997. "The Effect of Myopia and Loss Aversion on Risk Taking: An Experimental Test." Quarterly Journal of Economics, 112(2): 647-61.

Vallone, Robert, Dale Griffin, Sabrina Lin, and Lee Ross. 1990. "Overconfident Predictions of Future Actions and Outcomes by Self and Others." Journal of Personality and Social Psychology, 58(4): $582-92$.

Wood, Alison, and Maurice E. Schweitzer. 2010. "Can Nervous Nelly Negotiate? How Anxiety Causes Negotiators to Exit Early and Make Steep Concessions." Unpublished. 


\section{This article has been cited by:}

1. Julio González-Díaz, Ignacio Palacios-Huerta. 2016. Cognitive performance in competitive environments: Evidence from a natural experiment. Journal of Public Economics 139, 40-52. [CrossRef]

2. Juan Carlos Carbajal, Jeffrey C. Ely. 2016. A model of price discrimination under loss aversion and state-contingent reference points. Theoretical Economics 11:2, 455-485. [CrossRef]

3. Reto Foellmi, Stefan Legge, Lukas Schmid. 2016. Do Professionals Get It Right? Limited Attention and Risk-taking Behaviour. The Economic Journal 126:592, 724-755. [CrossRef]

4. Marcel Lichters, Claudia Brunnlieb, Gideon Nave, Marko Sarstedt, Bodo Vogt. 2016. The Influence of Serotonin Deficiency on Choice Deferral and the Compromise Effect. Journal of Marketing Research 53, 183-198. [CrossRef]

5. Alexander K. Koch, Julia Nafziger. 2016. Goals and bracketing under mental accounting. Journal of Economic Theory 162, 305-351. [CrossRef]

6. Stefan Moser, Oliver Mußhoff. 2016. Ex-ante Evaluation of Policy Measures: Effects of Reward and Punishment for Fertiliser Reduction in Palm Oil Production. Journal of Agricultural Economics 67:10.1111/jage.2016.67.issue-1, 84-104. [CrossRef]

7. Selcen Ozturkcan, Sercan SengunPleasure in Pain: How Accumulation in Gaming Systems Can Lead to Grief 41-55. [CrossRef]

8. Devin G. Pope, Justin R. SydnorBehavioral Economics 800-827. [CrossRef]

9. Per Engström, Katarina Nordblom, Henry Ohlsson, Annika Persson. 2015. Tax Compliance and Loss Aversion. American Economic Journal: Economic Policy 7:4, 132-164. [Abstract] [View PDF article] [PDF with links]

10. Björn Bartling, Leif Brandes, Daniel Schunk. 2015. Expectations as Reference Points: Field Evidence from Professional Soccer. Management Science 61, 2646-2661. [CrossRef]

11. Daniel Treisman. 2015. Income, Democracy, and Leader Turnover. American Journal of Political Science 59:10.1111/ajps.2015.59.issue-4, 927-942. [CrossRef]

12. Olof Rosenqvist, Oskar Nordström Skans. 2015. Confidence enhanced performance? - The causal effects of success on future performance in professional golf tournaments. Journal of Economic Bebavior \& Organization 117, 281-295. [CrossRef]

13. Daniel C. Hickman, Neil E. Metz. 2015. The impact of pressure on performance: Evidence from the PGA TOUR. Journal of Economic Behavior \& Organization 116, 319-330. [CrossRef]

14. Heiko Karle, Georg Kirchsteiger, Martin Peitz. 2015. Loss Aversion and Consumption Choice: Theory and Experimental Evidence. American Economic Journal: Microeconomics 7:2, 101-120. [Abstract] [View PDF article] [PDF with links]

15. Lars Lefgren, Brennan Platt, Joseph Price. 2015. Sticking with What (Barely) Worked: A Test of Outcome Bias. Management Science 61, 1121-1136. [CrossRef]

16. Deniz Igan, Marcelo Pinheiro, John Smith. 2015. A study of a market anomaly: "White Men Can't Jump", but would you bet on it?. Journal of Economic Bebavior \& Organization 113, 13-25. [CrossRef]

17. Andrej Stancak, Yuxin Xie, Nicholas Fallon, Patricia Bulsing, Timo Giesbrecht, Anna Thomas, Athanasios A. Pantelous. 2015. Unpleasant odors increase aversion to monetary losses. Biological Psychology 107, 1-9. [CrossRef]

18. Leif Brandes, Marc Brechot, Egon Franck. 2015. Managers' external social ties at work: Blessing or curse for the firm?. Journal of Economic Behavior \& Organization 109, 203-216. [CrossRef]

19. Brad R. Humphreys, Li Zhou. 2015. Reference-dependent preferences, team relocations, and major league expansion. Journal of Economic Behavior \& Organization 109, 10-25. [CrossRef] 
20. Aleksey Martynov, Donald J. Schepker. 2015. Risk Preferences and Asset Ownership: Integrating Prospect Theory and Transaction Cost Economics. Managerial and Decision Economics n/a-n/a. [CrossRef]

21. Philipp N. Herrmann, Dennis O. Kundisch, Mohammad S. Rahman. 2015. Beating Irrationality: Does Delegating to IT Alleviate the Sunk Cost Effect?. Management Science 61:4, 831. [CrossRef]

22. Jack L. Knetsch. 2015. The Curiously Continuing Saga of Choosing the Measure of Welfare Changes. Journal of Benefit-Cost Analysis 6, 217-225. [CrossRef]

23. Matthew Harding, Alice Hsiaw. 2014. Goal setting and energy conservation. Journal of Economic Bebavior \& Organization 107, 209-227. [CrossRef]

24. David Eil, Jaimie W. Lien. 2014. Staying ahead and getting even: Risk attitudes of experienced poker players. Games and Economic Behavior 87, 50-69. [CrossRef]

25. Keith M Marzilli Ericson, Andreas Fuster. 2014. The Endowment Effect. Annual Review of Economics 6, 555-579. [CrossRef]

26. Saurabh Bhargava, Ray Fisman. 2014. Contrast Effects in Sequential Decisions: Evidence from Speed Dating. Review of Economics and Statistics 96, 444-457. [CrossRef]

27. DENNIS COATES, BRAD R. HUMPHREYS, LI ZHOU. 2014. REFERENCE-DEPENDENT PREFERENCES, LOSS AVERSION, AND LIVE GAME ATTENDANCE. Economic Inquiry 52:10.1111/ecin.2014.52.issue-3, 959-973. [CrossRef]

28. Serkan Ozbeklik, Janet Kiholm Smith. 2014. Risk taking in competition: Evidence from match play golf tournaments. Journal of Corporate Finance . [CrossRef]

29. Heiko Karle, Martin Peitz. 2014. Competition under consumer loss aversion. The RAND Journal of Economics 45:10.1111/rand.2014.45.issue-1, 1-31. [CrossRef]

30. Ola Andersson, Håkan J. Holm, Jean-Robert Tyran, Erik Wengström. 2014. Deciding for Others Reduces Loss Aversion. Management Science 141223041315002. [CrossRef]

31. Kirk Doran. 2014. Are long-term wage elasticities of labor supply more negative than short-term ones?. Economics Letters 122, 208-210. [CrossRef]

32. J. Michael Collins, Carly Urban. 2014. The dark side of sunshine: Regulatory oversight and status quo bias. Journal of Economic Behavior \& Organization 107, 470. [CrossRef]

33. Craig R. Fox, Russell A. PoldrackProspect Theory and the Brain 533-567. [CrossRef]

34. Kevin M. Kniffin, Vince Mihalek. 2013. Within-series momentum in hockey: No returns for running up the score. Economics Letters . [CrossRef]

35. Tom Chang, Tal Gross. 2013. How Many Pears Would a Pear Packer Pack if a Pear Packer CouldPack Pears at Quasi-Exogenously Varying Piece Rates?. Journal of Economic Bebavior \& Organization . [CrossRef]

36. References 261-272. [CrossRef]

37. Alice Hsiaw. 2013. Goal-setting and self-control. Journal of Economic Theory 148, 601-626. [CrossRef]

38. Eldad Yechiam, Guy Hochman. 2013. Loss-aversion or loss-attention: The impact of losses on cognitive performance. Cognitive Psychology 66, 212-231. [CrossRef]

39. JICHUAN ZONG, JACK L. KNETSCH. 2013. VALUATIONS OF CHANGES IN RISKS: THE REFERENCE STATE AND EVIDENCE OF DIFFERENCES BETWEEN THE MEASURES. The Singapore Economic Review 58, 1350001. [CrossRef]

40. Nicholas C. Barberis. 2013. Thirty Years of Prospect Theory in Economics: A Review and Assessment. Journal of Economic Perspectives 27:1, 173-196. [Abstract] [View PDF article] [PDF with links]

41. Andrei Shleifer. 2012. Psychologists at the Gate: A Review of Daniel Kahneman's Thinking, Fast and Slow. Journal of Economic Literature 50:4, 1080-1091. [Abstract] [View PDF article] [PDF with links] 
42. Tanjim Hossain, John A. List. 2012. The Behavioralist Visits the Factory: Increasing Productivity Using Simple Framing Manipulations. Management Science 58, 2151-2167. [CrossRef]

43. Ran Abramitzky, Liran Einav, Shimon Kolkowitz, Roy Mill. 2012. ON THE OPTIMALITY OF LINE CALL CHALLENGES IN PROFESSIONAL TENNIS*. International Economic Review 53:10.1111/iere.2012.53.issue-3, 939-964. [CrossRef]

44. Vikram S. Chib, Benedetto De Martino, Shinsuke Shimojo, John P. O'Doherty. 2012. Neural Mechanisms Underlying Paradoxical Performance for Monetary Incentives Are Driven by Loss Aversion. Neuron 74, 582-594. [CrossRef]

45. David Gill,, Victoria Prowse. 2012. A Structural Analysis of Disappointment Aversion in a Real Effort Competition. American Economic Review 102:1, 469-503. [Abstract] [View PDF article] [PDF with links]

46. Quang Nguyen. 2011. Does nurture matter: Theory and experimental investigation on the effect of working environment on risk and time preferences. Journal of Risk and Uncertainty . [CrossRef]

47. K. M. Marzilli Ericson, A. Fuster. 2011. Expectations as Endowments: Evidence on ReferenceDependent Preferences From Exchange and Valuation Experiments. The Quarterly Journal of Economics . [CrossRef]

48. Katherine L. Milkman, Mary Carol Mazza, Lisa L. Shu, Chia-Jung Tsay, Max H. Bazerman. 2011. Policy bundling to overcome loss aversion: A method for improving legislative outcomes. Organizational Bebavior and Human Decision Processes . [CrossRef] 